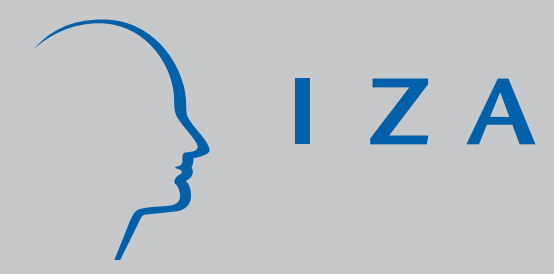

IZA DP No. 3600

From Giving Birth to Paid Labor: The Effects of Adult Education for Prime-Aged Mothers

Annette Bergemann

Gerard J . van den Berg

J uly 2008 


\title{
From Giving Birth to Paid Labor: The Effects of Adult Education for Prime-Aged Mothers
}

\author{
Annette Bergemann \\ VU University Amsterdam, IFAU Uppsala \\ and IZA \\ Gerard J. van den Berg \\ VU University Amsterdam, IFAU Uppsala, \\ CEPR, IFS, Netspar and IZA
}

\section{Discussion Paper No. 3600 \\ July 2008}

\author{
IZA \\ P.O. Box 7240 \\ 53072 Bonn \\ Germany \\ Phone: +49-228-3894-0 \\ Fax: +49-228-3894-180 \\ E-mail: iza@iza.org
}

\begin{abstract}
Any opinions expressed here are those of the author(s) and not those of IZA. Research published in this series may include views on policy, but the institute itself takes no institutional policy positions.

The Institute for the Study of Labor (IZA) in Bonn is a local and virtual international research center and a place of communication between science, politics and business. IZA is an independent nonprofit organization supported by Deutsche Post World Net. The center is associated with the University of Bonn and offers a stimulating research environment through its international network, workshops and conferences, data service, project support, research visits and doctoral program. IZA engages in (i) original and internationally competitive research in all fields of labor economics, (ii) development of policy concepts, and (iii) dissemination of research results and concepts to the interested public.
\end{abstract}

IZA Discussion Papers often represent preliminary work and are circulated to encourage discussion. Citation of such a paper should account for its provisional character. A revised version may be available directly from the author. 


\section{ABSTRACT \\ From Giving Birth to Paid Labor: The Effects of Adult Education for Prime-Aged Mothers}

Women without work after childbirth are at risk of losing their connection to the labor market. However, they may participate in adult education programs. We analyze the effect of this on the duration to work and on the wage rate, by applying conditional difference-in-differences approaches. We use Swedish matched longitudinal register data sets covering the full population. The Swedish adult education program is unprecedented in its size, and enrollment is universally available at virtually no cost. We focus on low-skilled women who have recently given birth. We take account of program accessibility, selection issues, course heterogeneity, the income received during adult education, parental leave, and child care fees. To understand the enrollment decision from the mothers' point of view, we use the estimates to calibrate a job search model.

JEL Classification: H43, J68, J64, J24, C14

Keywords: evaluation of adult education, job search model, female labor supply, wages, participation, unemployment, schooling, conditional difference-in-differences

Corresponding author:

Gerard J. van den Berg

Department of Economics

VU University Amsterdam

De Boelelaan 1105

1081 HV Amsterdam

The Netherlands

E-mail: gjvdberg@xs4all.nl

\footnotetext{
* We are grateful for helpful suggestions from Louise Kennerberg, Ann-Sofie Kolm, Laura Larsson, Linus Lindqvist, Daniela Lundin, Erik Mellander, Eva Mörk, Oskar Nordström-Skans, and participants in conferences in Uppsala, Essen, Budapest, Oslo, and Nuremberg, and a seminar at IFAU Uppsala. We thank Linda Petterson from the local employment office in Stockholm for giving us information on institutional features and on the decision process by case workers concerning reintegration. We thank Eva Mörk for generously giving us data on child care costs. Linus Lindqvist and Louise Kennerberg provided excellent help with the register data. We thank the Swedish National Labour Market Board (AMS) and Statistics Sweden (SCB) for their permission to use the data, and IFAU for financial support. The work in this paper is part of the ESRC Research Program "Advancing Programme Evaluation Methods".
} 


\section{Introduction}

During the past decades, a substantial amount of research has been conducted on the effect of labor market policies on the individual employment prospects (for overviews see e.g. Fay, 1996; Heckman, LaLonde and Smith, 1999; Martin and Grubb, 2001; and Calmfors, Forslund and Hemström, 2001). It is commonly acknowledged that effects are heterogeneous. Often, employment effects are larger for women (Bergemann and Van den Berg, 2008; Heckman, LaLonde and Smith, 1999; King, 2004). At the same time, participants with a low initial level of education typically benefit little from educational training (Heckman, LaLonde and Smith, 1999). The average employment rate of low-skilled individuals is substantially lower than of high-skilled individuals (66\% vs. $87 \%$ in 2005, see OECD, 2007), and among the former, the labor market figures for the group of low-skilled mothers with children are particularly weak. In 2005, the OECD average employment rate of women with less than secondary education is only $48 \%$ (OECD, 2007), and it is even lower if they have children (OECD, 2002).

The fact that mothers with young children constitute a particularly weak labor market group has potentially harmful long-run effects. They they may postpone a return to the labor market, for example until the child goes to school, or they may decide to have another child, and in the intervening years, the women may lose skills. This may further reduce their incentive to return to work. The ensuing income loss may negatively affect the child's development.

Our knowledge of labor market policy effects for this group is still very limited. In order to help these women to (re-)integrate in the labor market, and to raise their productivity, it is useful to obtain insights into the effectiveness of active labor market programs and education programs for this group. ${ }^{1}$ In this paper we examine the effect of participation in adult education programs on the duration to work and the labor income of low-skilled women who have recently given birth. Adult education is a relevant program for this group, because its access is not restricted to those entitled to unemployment insurance or welfare benefits, and it is therefore also open to mothers who do not have any source of income next

\footnotetext{
${ }^{1}$ Recently, life-long learning, adult education, and employability have become focal points in the labor market policies of many advanced economies (see e.g. OECD Employment Outlook 2004). It is expected that these economies will face more turbulent conditions than in the past, and that the development of novel production technologies will proceed at a sustained high speed, and this requires a flexible and suitably skilled workforce.
} 
to their partner's income. After a child caring phase, women may not eligible for unemployment insurance and the associated training programs provided by the employment offices. We focus on Sweden. Despite Sweden's well-known success in integrating skilled women into the labor market, it faces the same problems as basically all OECD countries with respect to women with less than upper secondary education. Sweden is well-suited for our analysis because of the magnitude of its adult education program Komvux. Sweden has a long tradition of training adult workers (see e.g. Ministry of Education, 1998; Friberg, 2000; and Ministry of Industry, 2001). In 1997 the program was modernized, and, in the period 1997-2002, the program was dramatically expanded in order to raise the skill level of low-skilled workers to a medium skill level, accordingly focusing on workers without work and with a low level of education. The size of the program is unprecedented: for example, over the period 1997-2000, the number of participants exceeded $10 \%$ of the labor force. Clearly, the program reflects a great deal of optimism about the extent to which an adult's human capital can be improved.

For the empirical analysis, we use a combination of longitudinal administrative register data which contains the full population of individuals in Sweden. The dataset matches detailed records from employment offices, unemployment insurance agencies, the income tax agency, and the adult education register. The latter contains records of all adult education courses that are followed.

The data include wage register data by employer. These enable the construction of an accepted-wage variable, which is obviously more informative on productivity effects than annual income from e.g. income tax registers. Wage-rate outcomes should not be subject to pre- and post-program participation dips. Concerning income out of work, we have separate information on unemployment benefits, adult education grants, parental leave benefits, and child care fees. The merging and simultaneous use of these data is a non-trivial task as it requires the combination of different sources. We use information on the eligibility and maximum entitlement period of the various income sources, by applying the relevant guidelines.

We do not address equilibrium effects of adult education. Albrecht, Van den Berg and Vroman (2008) calibrate the effects of Swedish adult education in the period 1997-2002, taking into account that the composition of jobs may respond in equilibrium to changes in the skill distribution. Björklund et al. (2005) show that Komvux recently led to a large flow of teachers from regular secondary education to adult education, and they argue that the program therefore may 
have generated substantial negative external effects on the quality of regular education. Such effects increase the social costs of the program, but addressing this is beyond the scope of the present paper. Since mothers with small children constitute a small fraction of all participants, it is unlikely that they contribute to equilibrium effects. We also do not aim to address the use of adult education by young individuals who left the regular school system with low educational levels, as a short-cut towards regular university education (see e.g. Björklund et al., 2005, and Ekström, 2003, for discussions). For this reason we exclude individuals aged below 25 .

To date, some studies have examined the effects of adult education in Sweden on individual labor market outcomes. Ekström (2003) estimates the effect on annual income of following adult education in the early 1990s, using straightforward difference-in-differences. She finds no positive income effects. Albrecht, Van den Berg and Vroman (2004) use similar methods to study effects on annual income and employment status, and they find no significant effects for women aged between 25 and 40. The latter study does not distinguish between recent mothers and other women, and its sample size may be too small to detect any effects. Several other studies have compared individual labor market outcomes between unemployed individuals who enroll in Komvux and unemployed individuals who enroll in labor market training, using propensity score matching or IV methods (see e.g. Axelsson and Westerlund, 1999, and Stenberg and Westerlund, 2008). The results depend strongly on the outcome measure, the evaluation method, and the type of labor market training and subpopulation considered.

Our estimation results indicate positive average effects. Because participation is not restricted, this raises the question why participation rates are low. We use the effect estimates to address the enrollment decision from the point of view of the mother. To this aim we calibrate a dynamic job search model augmented with adult education (see Eckstein and Van den Berg, 2007, for a survey on the structural estimation of job search models). The model distinguishes between effects on the rate at which jobs are found and effects on wages, and it allows for subsequent childbirths. Calibration requires additionally gathered information on the income associated with parental leave, the income grant during Komvux participation, and the costs of child care.

The model assumes that the enrollment decision is taken with an eye on the expected discounted future utility streams of the available options. These streams also depend on short-term outcomes that are typically ignored in the treatment 
effect literature. For example, an evaluation study may find that the average effect on the employment probability is positive, but for an eligible individual the present discounted value of participation may be negative because of the time needed to complete the program. Our analysis produces the additional interesting insight that small changes in the employment probability may be associated with large changes in the expected discounted value of program participation and relatively large changes in the exit rate to work. As a result, the unemployed individuals' present value can be greatly enhanced (and their unemployment duration can be substantially reduced) by a program that only leads to a slightly higher employment rate. This is because employment rates are typically rather unresponsive functions of the job offer arrival rate.

The outline of the paper is as follows. Section 2 discusses institutional features of the environment of recent mothers in Sweden, including the adult education program. Section 3 describes the data, and Section 4 outlines the estimation method we use and discusses the empirical implementation. Section 5 provides the estimation results. In Section 6 we analyze the enrollment decision using a structural job search model. Section 7 concludes.

\section{Institutional context}

\subsection{Adult education}

By now, many studies provide detailed descriptions of Komvux and their participants (see, for example, The National Agency for Education, 1999, Axelsson and Westerlund, 1999, Statistics Sweden, 2005, Skolverket, 2001, Stenberg, 2003, and Ekström, 2003). We therefore restrict ourselves to a summary.

Our observation window concerning participation in Komvux runs from 1997 to 2002. In this period, the adult education program was larger than ever before in Sweden. ${ }^{2}$ The main objective of the program was to increase the skill level of adult low-skilled workers to the medium skill level, thereby helping these individuals strengthen their position in the labor market. Here, low skilled means having an educational attainment below the level of a 3-year "gymnasium" degree, while medium skilled means having attained this level but not any education beyond that. The 3-year gymnasium degree roughly corresponds to the upper secondary

\footnotetext{
${ }^{2}$ The program in these years is also denoted as "Adult Education Initiative" and "Knowledge Lift".
} 
education level or senior high school. Since 1995 this is the lowest possible upper secondary school diploma, whereas before that many individuals left high school with a 2-year degree. The program particularly targets low skilled individuals that are unemployed or have withdrawn from the labor force. In fact, low-skilled employed and medium-skilled unemployed workers or individuals that have left the labor force are also often eligible for Komvux, and the enrollees contain many low-skilled employed workers, working part time or full time. Komvux also includes courses that do not aim at the attainment of a medium skill level but rather an improvement within the class of low skill sublevels.

Komvux focuses on the enhancement of general skills (for example, English, Swedish, and mathematics), as opposed to specific skills needed for particular professions. However, part of Komvux can be spent in orientation courses, vocational courses and work placement. In principle, it is possible to combine upper secondary courses with studies at an elementary level or with a program organized by the National Labor Market Board for the unemployed. The curriculums and grade criteria for the attainment of the medium skill level are roughly the same as in the regular upper secondary education system.

Komvux is organized at the municipal level. The organization may be joint with other municipalities. A municipality may purchase the services of education providers and/or cooperate with them. However, the municipalities are responsible for admission into Komvux. A single course typically starts twice a year and covers a half-year term. Many courses are offered on a full-time basis, but some are offered as a part-time course or, more specifically, as an evening course.

At the level of the individual, admission into Komvux is in principle free. The underlying view is that Komvux participation must be led by the demand for education. A participant should have ample scope for personal choice regarding the type of study and its timing and location. Whether one can participate in a desired course only depends on the availability of courses and on the entry skill level requirement. Recruitment of participants is sometimes carried out in cooperation with trade union organizations or local employment offices.

Komvux participants may be eligible for a range of income grants and financial study support grants. Most importantly, enrollees may receive "special education support" (UBS). The amount of this is equivalent to unemployment insurance (UI). UBS is only given to Komvux participants who are entitled to UI payments at the date of entry into the program. They must be registered as unemployed or have been employed in the last 5 years and being replaced at the 
workplace by a long-term unemployed individual. Moreover, the worker must be between 25-55 years old inclusive at the date of entry into the program and must study at the elementary or upper secondary level or attend an orientation course. The funding for the UBS grants is limited. Priority is given to workers without completed education at the elementary level and workers who intend to study Swedish, English, mathematics or social sciences. The grant is typically given for a maximum of one year. Because of the cap on UBS funding, a Komvux participant may not be granted UBS, and she may not know a long time in advance whether UBS will be granted to her or not.

Additionally, special adult study assistance and funding are available as a combination of a grant and a loan. Unemployed individuals can for example apply for a grant (SVUXA) in case they had been working for 3 year and are at least 21 years old. The grant amounts to $65 \%$ of the UI benefit or some minimum amount in case an individual is not eligible for unemployment benefits. The funding for SVUXA is limited. A first come, first serve rule is applied.

Employed individuals, individuals taking care of children/handicapped persons or handicapped individuals can apply for a different type of grant in case they study on a elementary or upper secondary level (SVUX). Again, funding is limited, with priority for individuals with a low education level who are in need of education and take a break from work in order to study.

Individuals who receive SVUXA or SVUX are entitled to a supplementary loan from the government. This loan and the grant together should be equivalent to UI.

Many participants rely on other financial resources than those listed above. Notably, they may depend partly or fully on a partner's income. An individual who is full-time in Komvux is considered to be out of the labor force unless he/she earns income on the side.

The state channels funds to the municipalities to finance Komvux. The amount of funding depends on the municipality's unemployment rate and skill level distribution, and on the scope of the municipality's program. A conservative estimate is that, in the first years of its existence, the state spent at least SEK 3.5 billion (US $\$ 400 \mathrm{M}$ ) per year on Komvux. This equals almost SEK 1000 per labor force participant in Sweden. The spending covered the creation of some 100,000 annual study slots as of 1997. In practice, the funding was more than sufficient to meet the demand for Komvux (see Statskontoret, 1999). This fact is important for our analyses because it implies that there was no quantity rationing. 
The following gives an indication of the size of the program in terms of numbers of enrollees. In the fall of 1997, 538,004 individuals (out of a population of $8 \mathrm{M}$ ) were (i) aged between 25 and 55 , and (ii) participated in the municipal adult education, or were unemployed (in the sense of actively searching), or participated in one or more training programs. About 220,000 of these participated in Komvux, and of these about 56,000 received UBS. About 35,000 Komvux participants were also registered as unemployed, so they are necessarily only part-time in Komvux. Another 5,000 participated both in Komvux and in employment training. The number of registered unemployed, including those participating in Komvux and/or training programs was about 330,000. For comparison, the number of pupils in regular upper secondary school was about 300,000, while the number of individuals participating in employment training programs was about $40,000 .{ }^{3}$ The figures do not sum to the total of 538,004 because some individuals fall into more than one category. Typically, the number of individuals enrolled in Komvux is about 50\% larger than the full-time equivalent of the number of occupied slots. This indicates that many enrollees are part-time participants. Skolverket (2001) provides a wealth of additional information on the composition of participants and courses.

\subsection{Unemployment insurance}

The eligibility requirements for unemployment insurance are as follows:

(i). General requirement: Being registered as unemployed, immediately available for work, and actively seeking paid work,

(ii). Work requirement: Having worked already for some time in the last 12 months or having finished full-time studies,

(iii). Membership requirement: Member of an Unemployment Insurance Fund

An individual is entitled to income-related unemployment benefits if she meets all three requirements. In the time period from 1996 to 2004 the replacement

\footnotetext{
${ }^{3}$ Participation in adult education is so large that the substantial increase in the unemployment rate in 2004 has been attributed to the cutbacks in the adult education program shortly before, the argument being that many individuals who would otherwise have been recorded as non-participants due to their participation in Komvux are now registered as unemployed instead (Swedish Institute, 2005). Note that this suggests that quantity rationing may be an issue after our observation window.
} 
ratio, the number of benefit days and the maximum level repeatedly changed (see Table 2.2). As an example, in 2001, benefits replaced up to $80 \%$ of the previous wage. The maximum benefits amounted to SEK 580 per day, or SEK 680 for the first 100 days. If individual met only the requirements (i) and (ii) the she could receive the so-called "basic amount". This equalled SEK 240 per day in 2001. Benefits were payable for up to 300 days in 2001, with a maximum of five days per calendar week. Payment is stopped in case of participation in an active labor market program or adult education program or in case of parental leave, and can be continued thereafter. The Unemployment Insurance Fund may decide to extend the period of benefit by an additional 300 benefit days. Anyone not granted another 300 days or having used up 600 benefit days and still being unemployed can obtain a place in the activity guarantee program. ${ }^{4}$ During participation in an active labor market policy (ALMP) program, individuals receive the so called "activity support" which equals the UI benefits level.

\subsection{Parental leave}

Parents have the right to be absent from work for a period of one and a half years after childbirth, without any compensation from the state. One may also leave work and receive "parental allowance" income, organized by the national insurance system. Specifically, if a parent is drawing a parental allowance (maximum of 450 days in 2001) as part of the national social insurance system she is entitled to leave work.

To be entitled to earnings-related parental insurance one has to have been working for a certain minimum number of days (about 3/4 of a year). In 2001 the social insurance paid $80 \%$ of the annual salary up to 7.5 times the so called

\footnotetext{
${ }^{4}$ This activity guarantee program was introduced in August 2000 for unemployed individuals who are, or risk becoming, long-term unemployed (more than 2 years of unemployment) (EUROSTAT, 2003). It intended to put an end to the vicious circle between unemployment measures and unemployment benefits. Participants receive intensive guidance in groups of 1015 people while having access to all standard labor market policy programs. A job seeker and her job counsellor are expected to jointly work out an action plan. All activities are full-time. The job seeker participates in the activity guarantee program until she finds a job for more than six months, begins a regular course of studies, or chooses to leave the program. Those who are eligible for income-related benefits from an Unemployment Insurance Fund receive activity support during participation in the activity guarantee program (payment by the social insurance) in the same amount. Others receive SEK 143 per day.
} 


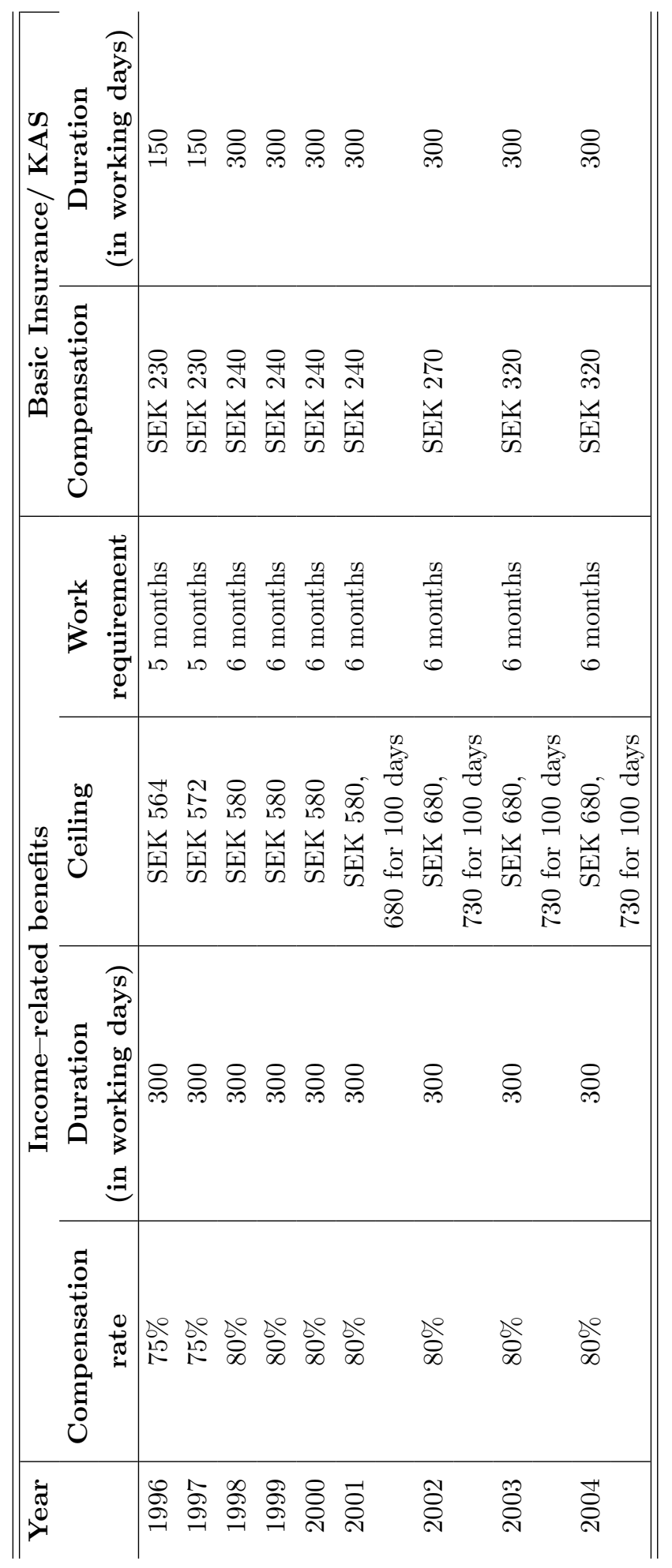

Table 1: Unemployment Benefits

Source: Swedish Institute 1997a, 2001, 2005; Regnér, 2002; Bennmarker, Carling, and Homlund, 2005; and EUROSTAT, 2003. 
"higher price base amount", which for 2001 is SEK 36,900. The higher price base amount is linked to the consumer price index in order to ensure that the benefits maintain their value (Ministry of Health and Social Affairs, 2001). The earnings related parental allowance is based on the estimated earnings the individual would have had during the parental leave.

In 2001, parents who received a baby are entitled to 360 days of earningsrelated benefits. Parents on low income or no income at all receive a minimum guaranteed benefit of SEK 60 per day. In an additional 90 days, parents receive benefits at the universally applicable flat rate that also amounts to SEK 60 per day in 2001. The 450 days of cash benefits are divided equally among parents. A parent may transfer 180 days to the other parent. In contrast to the unemployment benefit system, the days considered also include Saturdays and Sundays. In the time period from 1995 to 2004, the replacement ratio, benefit days and payment ceiling underwent some changes (see Table 2.3).

Finally, all parents who were full time employed were given the legal right to reduce work hours at own cost to $75 \%$ until the child is 8 years old.

\subsection{Child care}

Since 1995, municipalities are legally obliged to supply day care for parents who work or study. During 2001 to 2002 a number of reforms were introduced with the aim of improving access to child care for unemployed and those taking parental leave to look after offspring (unemployed: 1 July 2001; parents taking parental leave: 1 January 2002; see Ministry of Education, 2005). In addition, since 1 January 2003, for 3 hours per day during school term, attendance is free of charge for those aged 4-5 years (this is called universal pre-school).

In general, child care in Sweden is not for free, and during the 1990s child care actually became more expensive. Fees were raised and increasingly linked to family income as well as the child's hours of attendance. This new fee structure worked as a disincentive to find work, for mothers who were unemployed or out of the labor force. Often, a considerable amount of the increase in family income went into child care fees (Swedish Institute, 2004). To counteract this development, a system of maximum child care fees was introduced on 1 January 2002. This involved a ceiling for the amount parents could be required to pay for their child (Skolverket, 2003).

(i). At pre school facilities, the fee charged is less than or equal to $3 \%, 2 \%$ or 


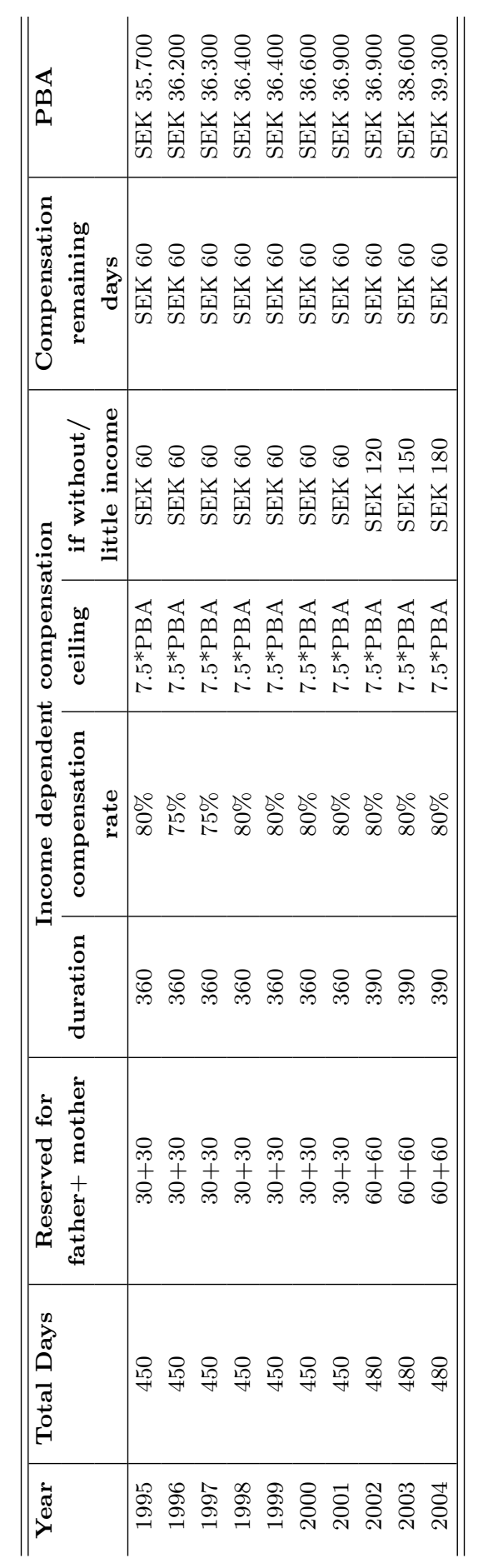

Table 2: Parental Leave Benefits

Source: Swedish Institute, 1997b, 2000; Ministry of Health and Social Affairs 2003, 2005; National Social Insurance Board 2001, 2002, 2003, 2004, 2005, see http://www.forsakringskassan.se/ 
$1 \%$ of the family's income, depending on whether it is the first, second or third child. There is a maximum amount of SEK 1,140 per month for the family's first child, SEK 760 for the second child, and SEK 380 for the third child.

(ii). In the school age child care system, the fee charged should be less than or equal to $2 \%$ or $1 \%$ of the family's income, depending on whether it is the first or second child. The fee should not be higher than SEK 760 per month for the family's first child and SEK 380 for the second and third child.

Local authorities can decide whether they introduce the fee ceiling. The state offers compensation to those who do. In the first year, 288 out of 290 local authorities joined. The remaining two joined later.

The maximum fee substantially reduced the amount parents pay for child care. In 2001, fees contributed $18 \%$ to the gross child care cost. In 2002, after the reform, the percentage declined to $11 \%$. The new fee system increases the subsidy rate for most families and should tend to increase the labor force participation for mothers (Kolm and Lazear, 2006). However, an evaluation of the short-run effects of the reform does not show a significant increase of the employment rate for mothers. (Lundin, Mörk and Öckert, 2007).

\section{The data}

\subsection{The data registers}

Our dataset covers the population of inhabitants in Sweden. These individuals have been longitudinally traced in a number of different administrative registers covering (subsets of) the period 1994-2003. Our dataset matches the records of individuals across these registers.

The first register is the official Swedish register of labor market statistics RAMS. It is obtained from yearly income tax declarations. It includes information from the population register, which is used to create the sample. The register provides observations on an annual basis of various types of income that each individual may receive together with the months an individual may work. Specifically, we observe individual wage incomes and income from self-employment. The RAMS data also provide information on the employer. More information on income definitions is provided in Subsection 3.2. 
The second register is the so-called HÄNDEL dataset, which is based on registers at the employment office and is compiled by the Swedish Labor Market Board. It includes all individuals who ever registered as unemployed starting from September 1991. Registration is voluntary but is required in order to receive or apply for unemployment compensation or to participate in any type of labor market program, so in fact almost all unemployed are in these data (according to Carling, Holmlund and Vejsiu, 2001, more than $90 \%$ of the individuals who are ILO-unemployed according to labor force surveys also register at the employment offices).

The HÄNDEL data provide labor market histories for all its individuals on a daily basis, with dates of transitions between different labor market states and between open unemployment and participation in training programs and work experience programs. However, because participation in Komvux is regarded as an out-of-the-labor-force activity, HÄNDEL by itself does not allow for observation of spells of Komvux participation.

The third register (ASTAT) is from the unemployment insurance fund. It provides week by week information on the amount of unemployment compensation that is received.

The fourth register (KOMVUX) contains individual records on participation in any adult education program. These data are available for the years 1985-2002. From this we can follow participation in adult education on a basis of six-month periods at the individual level. Therefore, for all individuals for all semesters there is a specific variable recording whether the individual has been in Komvux in that semester. This includes those whose participation is subsidized as well as those who do not get subsidy. There is also information about whether the course(s) taken were day or evening courses, and about the municipality where the course was taken. For the years 1997-2002, additional detailed information on adult education experiences is available, like course content and hours attended. The register is available until and including the year 2002.

The fifth register (LOUISE: Database for Education, Income and Employment) contains detailed information on additional income sources on an annual basis (i.e. educational grant, paternity leave benefits, social allowance) and individual specific information (i.e. education, municipality and marital status). These data are collected by Statistics Sweden.

In addition, we use the "generation register". This data set provides information on the month of birth and identifiers for the parents. 


\subsection{Variable definitions, sample selection, and data sum- maries}

The Appendix to the paper contains a detailed description of the data registers, the variables in the registers, and the way we select our sample and construct the variables of interest from these registers. We also provide an account of the practical problems and inconsistencies that arose. In this subsection we focus on the main issues.

We restrict attention to women who are aged between 25 and 45 on December 31,1996 . This is because individuals below 25 have access to different active labor market programs, educational opportunities, and remuneration eligibilities while unemployed or in education (see e.g. Larsson, 2003). As noted in Section 1, young individuals who left the regular school system with low educational levels may use Komvux as a short-cut towards regular university education (see e.g. Ekström, 2003). With the age restriction we basically avoid evaluating these cases. In the event, that we nevertheless observe women going to university we exclude them from our analysis.

We only consider low-skilled individuals, i.e. having less than three years of upper secondary education in 1996. This restriction is consistent with the main Komvux objective in 1997-2002 to raise the skill level of low-skilled workers. We exclude individuals who went into Komvux in the time between 1996 and the moment of childbirth, since these may have already increased their skill level in that time interval. The modernization of Komvux was implemented starting in the second half of 1997 (which we denote by 97-II). We take this as the first possible treatment semester. We focus on women who have given birth in 1996 and after. The major increase in the size of Komvux ended at the end of 02II. Since we do not have many time periods after 02-II in some essential data registers, we decide to stop following individuals after 03-II. In order to be able to observe women for a sufficient amount of time after childbirth, we restrict attention to women giving birth in 00-II or earlier.

We assume that each childbirth in this period of 96-I to 00-II is immediately followed by a 10-month maternity leave period. This equals the average length of the maternity leave period in those years (Eriksson, 2005). Since then the average length has been increasing, and this has led to the common perception that women tend to have maternity leave periods of at least one year. ${ }^{5}$ After mater-

\footnotetext{
${ }^{5}$ In a sensitivity analysis with respect to the treatment effects, we also checked whether our
} 
nity leave, the individual can move between the states of Komvux, unemployment, non-participation, employment, "bearing another child" and participation in labor market training. We focus on the effects of Komvux for women who are unemployed or out-of-the labor force at some point after the maternity leave. We stop following individuals after a transition into "bearing another child" or labor market training program. ${ }^{6}$

We decided to time-aggregate the outcome variables into a semester format. We therefore assign one state to each individual in each semester. The assigned state is the most dominant state among the actually occupied states in that semester, in the sense of covering the largest number of days (see the Appendix for details). We also assign an income variable to this most dominant state. The calibration analysis also requires income levels in counterfactual states.

The construction of the employment income (i.e. wage) variable deserves some discussion. These are taken from firm registers. Specifically, the employment information and the wage data is taken from the wage information which firms are obliged to give to the tax authorities. For every calendar year, all firms have to inform the tax authorities about the employment duration of each employee (on a monthly basis) and on his/her yearly wage. The employment duration of an individual in a specific year is given by the start month and the end month. In addition, there is a variable for the wage paid during this employment relationship.

\subsection{Descriptive statistics}

Table 3 gives an overview over the labor market situation of the low-skilled mothers in our sample. Their employment rate in the first half of 1995 equals $49 \%$. When comparing the distribution of labor market states before and after the maternity leave, it becomes obvious that the proportion of employed women stays relatively constant with around $62 \%$ having a job. The proportion of unemployed vs. out-of-the-labor-force changed slightly. Before maternity leave $33 \%$ were unemployed and $5 \%$ out-of-the labor force, whereas two semesters after the maternity leave $31 \%$ were unemployed and $8 \%$ were out-of-the-labor-force, indicating some loss of labor market attachment among those women.

The relatively low employment rate in 1995-I compared to the employment

results change when assuming a 12-month maternity leave period. And in fact, they did not.

${ }^{6}$ See Table 12 in the Appendix for a detailed summary of the sample selection criteria. 
rate before and after maternity leave is partly due to the worse labor market situation in 1995 compared to later years and partly due to the conditioning in the second perspective on being before and after maternity leave and not during.

These figures indicate that child birth does not increase the risk of losing a job, at least not immediately after the child is born. This might raise the question why low skilled mothers have such a low employment rate. One reason could be that it is more difficult to return for these women to work once they have lost their work. Note, however, that in our analysis, we take the low employment rate as given and focus on whether adult education can help to improve the labor market situation of low skilled mothers.

Table 3 also depicts participation rates in adult education. Hereby, we distinguish two different forms of participation. Participation in the broader sense encompasses all forms of participation i.e as soon as attendance is at least 1 hour. In contrast, participation in the narrower sense only includes women who attend courses of adult education for a significant amount of time and intensity, which we define as participation for at least 350 hours during 2 to 4 semesters. This is equivalent to at least half a year in a regular upper-secondary school.

The highest participation rate in adult education can be found among women who are unemployed after maternity leave. $39 \%$ of these women go at a later point in time into the Komvux program for at least 1 hour. However only 19 $\%$ go into Komvux for a significant amount of time and intensity. The group of women who are out-of-the-labor-force have the second highest participation rate with about $23 \%$ for at least 1 hour, but only $9 \%$ for a significant amount of time and intensity. Although women who are employed after maternity leave have the lowest probability of going in Komvux, nevertheless still 17\%, respectively $7 \%$ participate.

In our evaluation we focus on women who are either unemployed or out-of-the labor force just before participation in Komvux, estimating the treatment effects separately for these two groups. We consider an individual as participant if she goes into Komvux according to the narrower definition. The control group of nonparticipants consists of those who are also either unemployed or out-of-thelabor-market and do not follow a course of Komvux at all during our observation window.

Concerning unemployment, our sample consists of approximately 23.000 women whereof approximately 4,000 (17\%) attended Komvux (see Table 4).

Among those who did not enter Komvux, $24 \%$ are employed 5 years after their 
Table 3: Labor Market Situation of Low-Skilled Mothers

\begin{tabular}{|c|c|c|}
\hline Employment rate in $1995-I$ & $49 \%$ & \\
\hline \multicolumn{3}{|c|}{ Employment states in semester before maternity leave: } \\
\hline employed & $62 \%$ & \\
\hline unemployed & $33 \%$ & \\
\hline out of the labor force & $5 \%$ & \\
\hline \multicolumn{3}{|c|}{ Employment states two semester after maternity leave: } \\
\hline employed & $61 \%$ later in Komvux & $\begin{array}{l}\text { in the broader sense: } 17 \% \\
\text { in the narrower sense: } 7 \%\end{array}$ \\
\hline unemployed & $31 \%$ later in Komvux & $\begin{array}{l}\text { in the broader sense: } 39 \% \\
\text { in the narrower sense: } 19 \%\end{array}$ \\
\hline out-of-the labor force & $8 \%$ later in Komvux & $\begin{array}{l}\text { in the broader sense: } 23 \% \\
\text { in the narrower sense: } 9 \%\end{array}$ \\
\hline
\end{tabular}

Note: Recall that here as well as in the other tables below, employment rates and employment states are semesterly constructs.

maternity leave, $15 \%$ are unemployed, $5 \%$ are out-of-the-labor-force, $26 \%$ had another child in the meantime, $10 \%$ went into a labor market training program, and $20 \%$ can not be observed anymore due to the end of the observation window.

Participants, in contrast, are more likely to be observed either employed (35\%) or unemployed (32\%) 5 years after maternity leave, less often to have another child (9\%), go less often into labor market training $(4 \%)$ or reach the end of the observation window (15\%). Only, the proportion of women who leave the labor force is similarly high among the participants and the nonparticipants. Once former participants found a job they have a slightly higher wage than nonparticipating women. Another noteworthy fact is that the proportion of Scandinavian and Non-Scandinavian women is relatively similar among the participants and then nonparticipants.

When participating, $88 \%$ of the unemployed women received a grant (see Table 5). Only $9 \%$ of the women followed a course trajectory that contained more than 25\% Mathematics. Also the proportion of women following English of Swedish more than a quarter of the time $(32 \%)$ or some orientation courses $(27 \%)$ is not particularly high. The highest proportion of women $(86 \%)$ follow 
other courses than Mathematics, English and Swedish, or orientation courses for a significant amount of time.

Table 4: Evaluation Sample: Unemployed Before (Potential) Participation

\begin{tabular}{lc|c}
\hline \hline & $\begin{array}{c}\text { participants } \\
17 \%\end{array}$ & $\begin{array}{c}\text { nonparticipants } \\
83 \%\end{array}$ \\
\hline $\begin{array}{l}\text { Country of origin: } \\
\text { Scandinavian }\end{array}$ & $89 \%$ & $88 \%$ \\
\hline \hline Employment states 5 years after maternity leave: & & \\
(Excluding participants who still need to finish Komvux) & & \\
Employment & $35 \%$ & $24 \%$ \\
Unemployment & $32 \%$ & $15 \%$ \\
Out of the labor force & $5 \%$ & $5 \%$ \\
Right-censored because of childbirth & $9 \%$ & $26 \%$ \\
Right-censored because of training program & $4 \%$ & $10 \%$ \\
Right-censored because of observation window & $15 \%$ & $20 \%$ \\
\hline Average semesterly wage & SEK 82,800 & SEK 80,200 \\
\hline \hline
\end{tabular}

Our sample contains approximately 3.000 Non-Scandinavian women of whom $17 \%$ participated in Komvux, a similar participation rate as for the Scandinavian women. The main differences between the Non-Scandinavian and the Scandinavian women lie in the lower employment rate of Non-Scandinavian five years after maternity leave (see Table 6) and a lower wage once their are employed. This applies to both, participants and nonparticipants. The lower employment rate finds its counterpart in a higher rate of being out-of-the-labor-force. Another remarkable difference can be found in a lower probability of Non-Scandinavian to receive a grant ( $73 \%$ vs. $88 \%$ ) (see Table 7 ). In addition, once they participate, they tend to study Swedish or English and are are more likely to follow orientation courses compared to Scandinavian women.

Women who are out-of-the-labor-force at some point after maternity leave display quite a different labor market behavior compared to those who are unemployed (see Table 8). Our sample consists of around 19,000 women of whom only $3 \%$ participate in Komvux. Of the participants, $40 \%$ are in employment 5 
Table 5: Course Characteristics: Unemployed Before (Potential) Participation

\begin{tabular}{lc}
\hline \hline Receive grant & $88 \%$ \\
More than 25\% Mathematics & $9 \%$ \\
More than 25\% Swedish or English & $32 \%$ \\
Some orientation course & $27 \%$ \\
More than 25\% other courses & $86 \%$ \\
\hline \hline
\end{tabular}

Table 6: Evaluation Sample: Non-Scandinavian Unemployed Before (Potential) Participation

\begin{tabular}{lc|c}
\hline \hline & $\begin{array}{c}\text { participants } \\
17 \%\end{array}$ & $\begin{array}{c}\text { nonparticipants } \\
83 \%\end{array}$ \\
\hline $\begin{array}{l}\text { Employment states 5 years after maternity leave: } \\
\text { (Excluding participants who still need to finish Komvux) }\end{array}$ & & \\
Employment & $29 \%$ & $20 \%$ \\
Unemployment & $30 \%$ & $16 \%$ \\
Out of the labor force & $8 \%$ & $8 \%$ \\
Right-censored because of childbirth & $9 \%$ & $22 \%$ \\
Right-censored because of training program & $7 \%$ & $13 \%$ \\
Right-censored because of observation window & $18 \%$ & $21 \%$ \\
\hline Average semesterly wage & SEK 80,100 & SEK 77,700 \\
\hline \hline
\end{tabular}

years after parental leave, whereas $17 \%$ are unemployed. In contrast $28 \%$ of the nonparticipants are in employment and $4 \%$ unemployed. It is noteworthy that the proportion of Scandinavian is lower among the participants than among the nonparticipants and that right censoring due to participation in a labor market training program among the nonparticipants is particularly low with $2 \%$. The wage difference is comparable to the unemployment sample. Similarly comparable is the observations that participants have less often a child (9\%) than nonparticipants (26\%)

With respect to the course characteristics (see Table 9), it should be noted that a smaller percentage of the out-of-the labor market sample receives a grant 
Table 7: Course Characteristics: Non-Scandinavian Unemployed Before (Potential) Participation

\begin{tabular}{ll}
\hline \hline Receive grant & $73 \%$ \\
More than 25\% Mathematics & $11 \%$ \\
More than 25\% Swedish or English & $55 \%$ \\
Some orientation course & $36 \%$ \\
More than 25\% other courses & $54 \%$ \\
\hline \hline
\end{tabular}

compared to the unemployment sample, which is in accordance to the grant regulations (see section 2.1. In addition, one should note that a slightly higher percentage attends courses of elementary skills like mathematics and English and Swedish.

Table 8: Evaluation Sample: Out-of-the-Labor-Force Before (Potential) Participation

\begin{tabular}{lc|c}
\hline \hline & $\begin{array}{c}\text { participants } \\
3 \%\end{array}$ & $\begin{array}{c}\text { nonparticipants } \\
97 \%\end{array}$ \\
\hline $\begin{array}{l}\text { Country of origin: } \\
\text { Scandinavian }\end{array}$ & $78 \%$ & $89 \%$ \\
\hline \hline Employment states 5 years after maternity leave: & & \\
(Excluding participants who still need to finish Komvux) & & \\
Employment & $40 \%$ & $28 \%$ \\
Unemployment & $17 \%$ & $4 \%$ \\
Out of the labor force & $9 \%$ & $12 \%$ \\
Right-censored because of childbirth & $9 \%$ & $26 \%$ \\
Right-censored because of training program & $3 \%$ & $2 \%$ \\
Right-censored because of observation window & $22 \%$ & $28 \%$ \\
\hline Average semesterly wage & SEK 83,000 & SEK 80,900 \\
\hline \hline
\end{tabular}


Table 9: Course Characteristics: Out-of-the-Labor-Force Before (Potential) Participation

\begin{tabular}{ll}
\hline \hline Receive grant & $69 \%$ \\
More than 25\% Mathematics & $11 \%$ \\
More than 25\% Swedish or English & $38 \%$ \\
Some orientation course & $27 \%$ \\
More than 25\% other courses & $76 \%$ \\
\hline \hline
\end{tabular}

\section{Estimation Method and Implementation}

We apply the widely used conditional difference-in-differences estimator (CDiD) in order to estimate the treatment on the treated effects (see for example Heckman, Ichimura, Smith and Todd 1998, and Bergemann, Fitzenberger and Speckesser 2008)). It has been shown that this estimation method is very well suited to handle selectivity issues which are common in evaluation studies using nonexperimental data (see Heckman, Ichimura, Smith and Todd, 1998 and Smith and Todd, 2005). The conditional difference-in-differences estimator combines matching with taking difference-in-differences. The matching part of this estimation approach controls for selection on observables. Here, we implement matching by estimating a propensity score for participation in Komvux, which we then use in our local linear kernel estimation in order to match treated individuals to nonparticipants. 7

We only match treated to those nontreated in case the nontreated gave birth in the same semester and they have the same employment status in the semester before the treated go into Komvux. ${ }^{8}$ These two conditions secure that the individuals face the same labor market conditions at the time around birth and they experience the same labor market dynamics shortly before going in Komvux. It has been proven that it is essential to take these conditions into account in order

\footnotetext{
${ }^{7}$ We use Silverman's Rule of Thumb for the bandwidth choice (Silverman 1986). A sensitivity analysis showed that the results do not change when using half or double of the bandwidth.

${ }^{8}$ In our application of this approach, we found that those women, who go into Komvux immediately after parental leave are very similar in terms of their treatment effect to those who are unemployed. We therefore included those to the unemployment sample but naturally then conditioning on being in parental leave in the semester before.
} 
to receive reliable estimates for treatment parameters (see for example Heckman and Smith 1999). We estimate the propensity score on the basis of a parametric probit where we include time-invariant characteristics such as age in 1996, number of children, education, origin, and the income of the partner in the first semester of 1996.

We consider selection on time invariant unobservable characteristics by implementing the difference-in-differences estimator in matched samples. The preprogram difference is calculated as an average of the two semesters before birth. Our inference uses a bootstrap approach with 200 resamples to take account of the estimation error in the propensity score.

We use two different outcome variables, employment rate and semesterly wages. When estimating the treatment effect on wages we condition on the treated and the matched nontreated to be employed - otherwise we would not observe their wages. By conditioning on the employment status we are able to avoid problematic settings, for example assuming a wage/income of 0 , for those individuals that are not employed. Such an imputation would make it difficult to interpret the estimates of the treatment parameters as productivity effects, which we, however, aim at.

Finally, it should be noted that going in training as a program of ALMP and having another child are treated as a censoring event, i.e. starting from this point on the individuals are not included anymore in the treatment or nontreatment group.

We conducted a large number of additional sensitivity analysis concerning specific settings of our approach. For example, treating all types of participation in ALMP as censoring events (instead of being unemployed) does not change the results. Furthermore, we checked how the participation definition of being in Komvux influences the results. When including women who only follow Komvux for one semester or for less than 350 hours into the control group the results stay the same. The effects become somewhat smaller when including courses that last for more than 4 semesters. Finally, we also checked how sensitive the results are with respect to the time-aggregation of the different labor market spells within a semester into semesterly outcomes (see Appendix concerning details of these). It turns out that the evaluation results are also very stable concerning changes of these settings. For example, it does not matter whether one gives priority to unemployment or employment, when there are overlaps of these two spell types. 


\section{Empirical results}

We discuss the estimation results by way of graphical illustrations, see Figures 1 to $7 .^{9}$ The basic set up of the figures is the following: The thick curved line displays the CDID-estimates relative to the start of participation. The dotted line around shows the $95 \%$ confidence-interval which is estimated with the aid of 200 bootstrap resamples. The success criterion is either the employment probability or wages. ${ }^{10}$

The time at which the evaluation starts depends on the success criterion. For the employment rate we are able to estimate the treatment effect starting immediately with begin of the participation. This approach takes the view that the time in the program is lost time on the labor market. However, concerning the wage effect we have to take a different view, as the main part of the participants do not work during participation. Therefore we are only able to estimate the wage effects in case all participants have left Komvux which is in semesters 5 after the start of the participation.

Where possible, we present results for participating in adult education on average and also distinguish different course types. Hereby, we will look particularly whether courses that contain a significant amount of Mathematics, Swedish or English, some orientation course or a significant amount of other topics might work particularly well for the actual participating women.

We first discuss the average treatment effect for the women who went into Komvux from unemployment or directly from parental leave. The results of the estimated effects on the employment probability are shown in Figure 1. The average effect over all program types is negative until 4 years after the start of the program. Only after 5 years, the treatment-on-the-treated effect becomes positive and significantly different from zero. At the end of the observation period, i.e. 6.5 years after the start of the program the participation increased the employment rate by 10 percentage points.

By contrast, the effect on the wages is already positive three years after the start of the program. Five years after the start, the wages has increased by approximately 10.000 SEK per semester due to the participation in adult education. As anticipated in Section 1, the estimated wage effect does not display the post-

\footnotetext{
${ }^{9}$ The tables with coefficient estimates for the conditional difference-in-differences outcome equations are available upon request.

${ }^{10} \mathrm{We}$ only document estimates that are based on at least 50 observations.
} 
program dip typically encountered in studies of effects on annual earnings. This is because the latter outcome is confounded by the sluggish employment adjustment whereas the wage outcome is not. Of course, our time-aggregation into semesters may still lead to some apparent gradualness in the wage effect during the first years after participation. In any case, as a by-product of the paper, we may conclude that wage data allow for a faster program evaluation than earnings data, if interest is in productivity effects.

Figure 1: Average Treatment-on-the-Treated Effect on Employment, if Unemployed or in Parental Leave before Participation in Komvux - Average over All Program Types

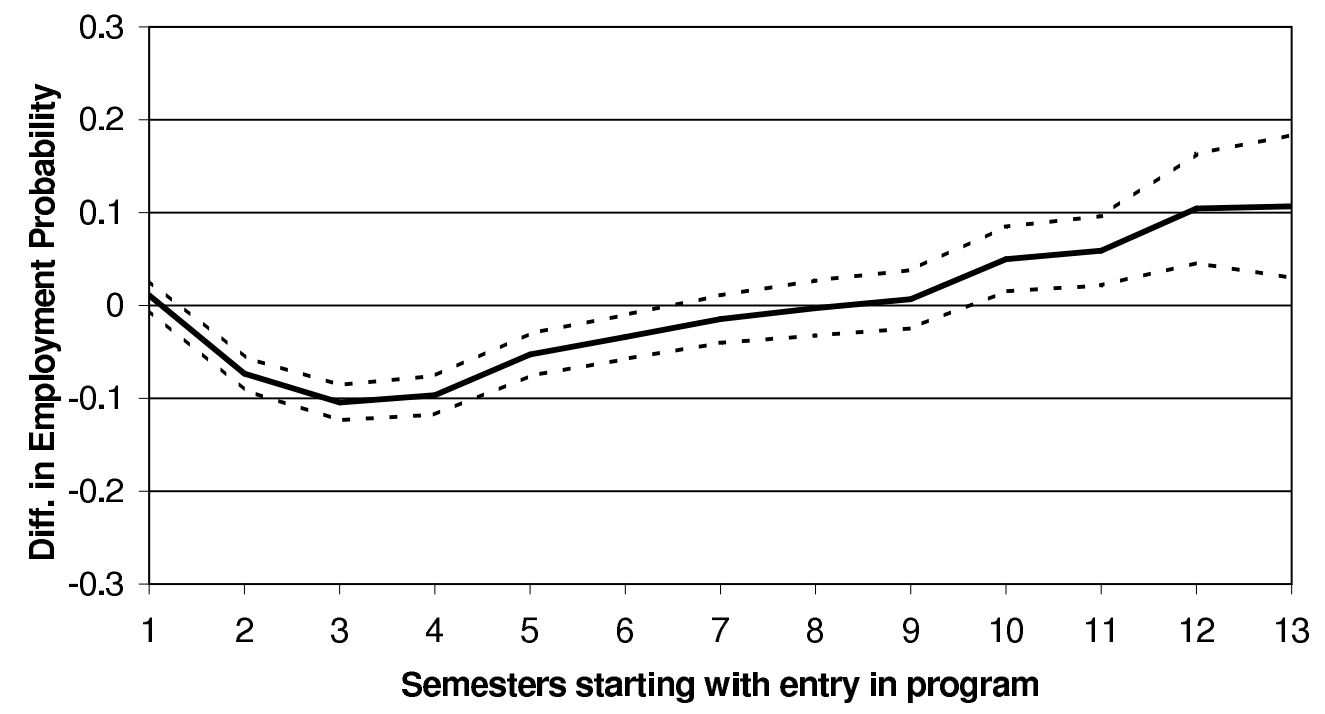


Figure 2: Average Treatment-on-the-Treated Effect on Wage, if Unemployed or in Parental Leave before Participation in Komvux - Average over All Program Types

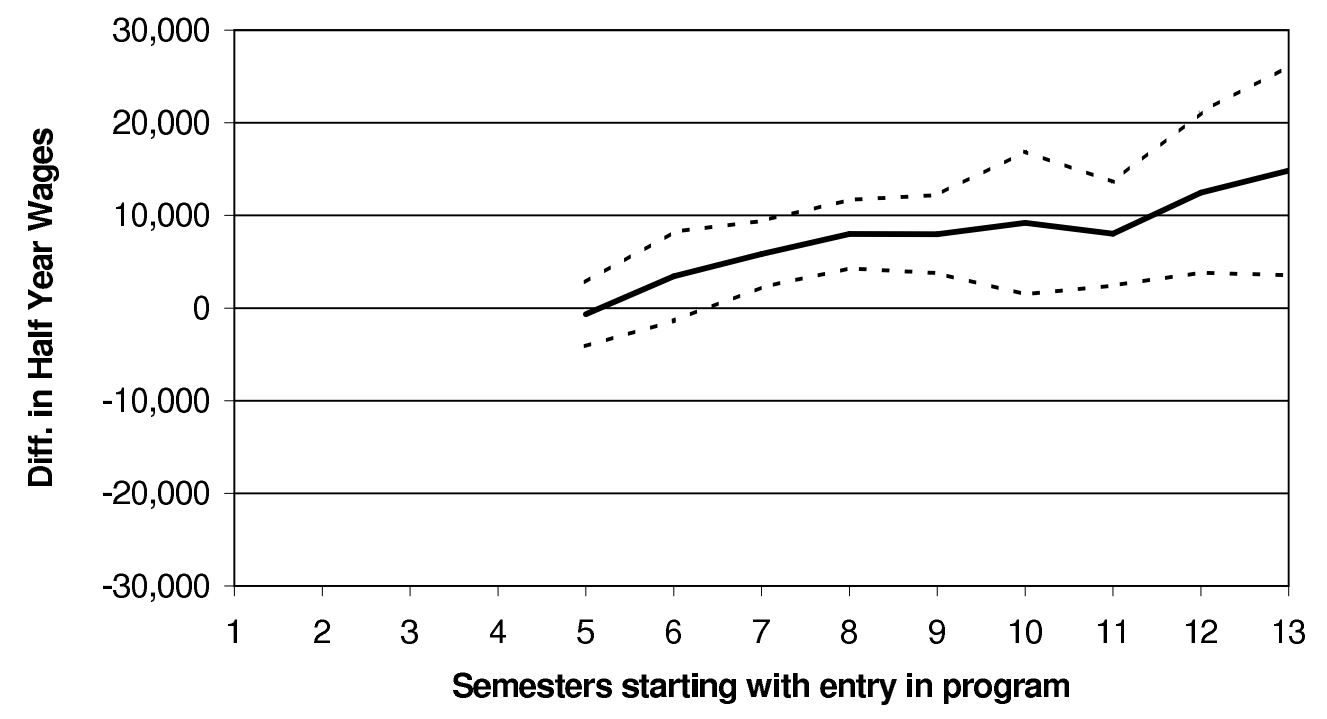



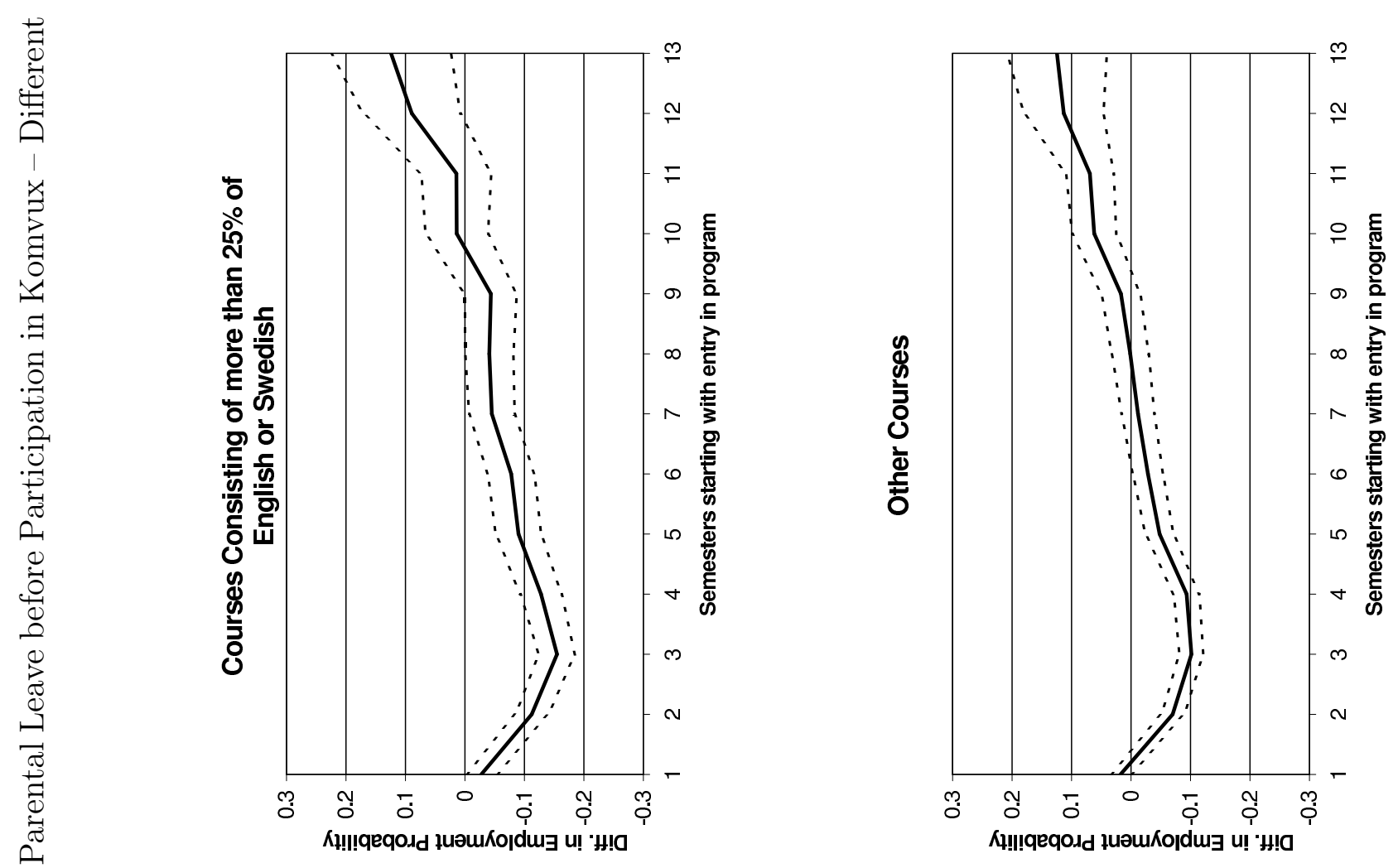

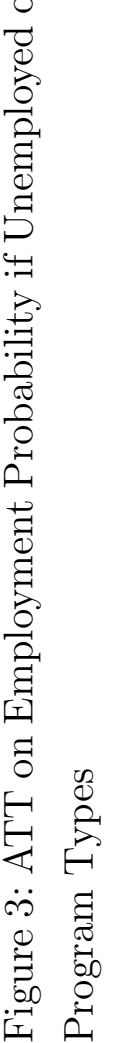
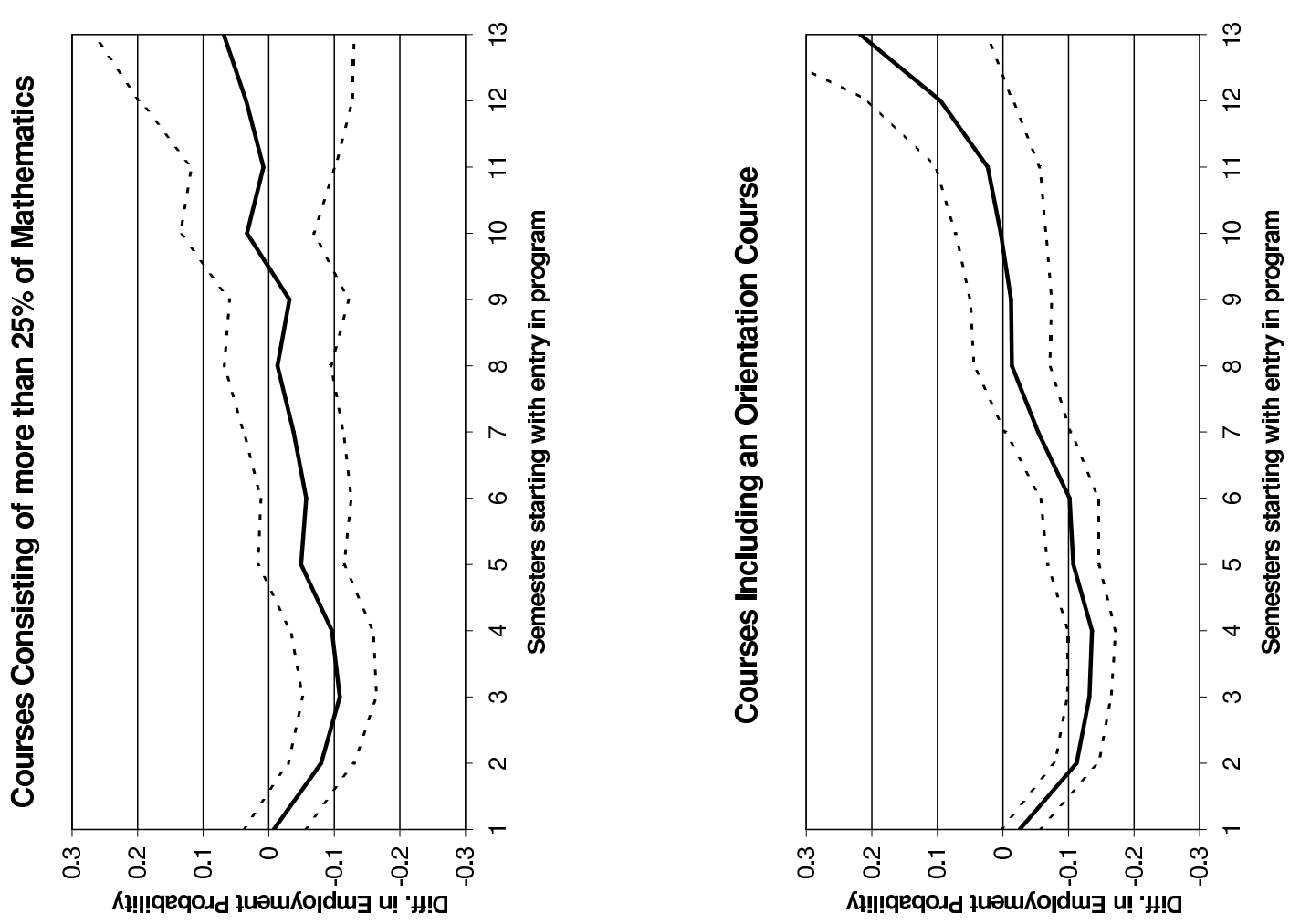

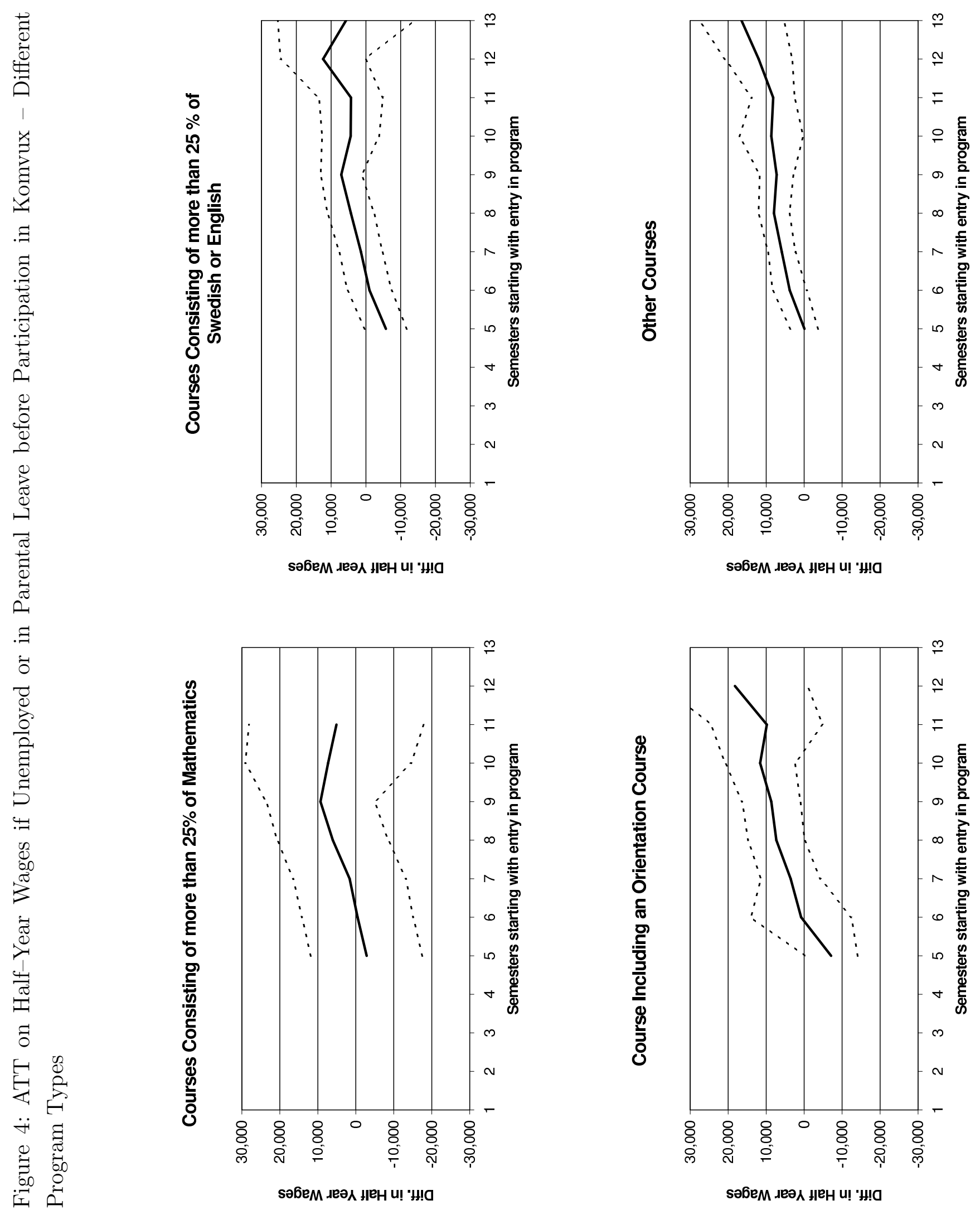
Figure 5: Average Treatment-on-the-Treated Effect for Non-Scandinavian Women if Unemployed or Parental Leave before Participation in Komvux - Average over All Program Types
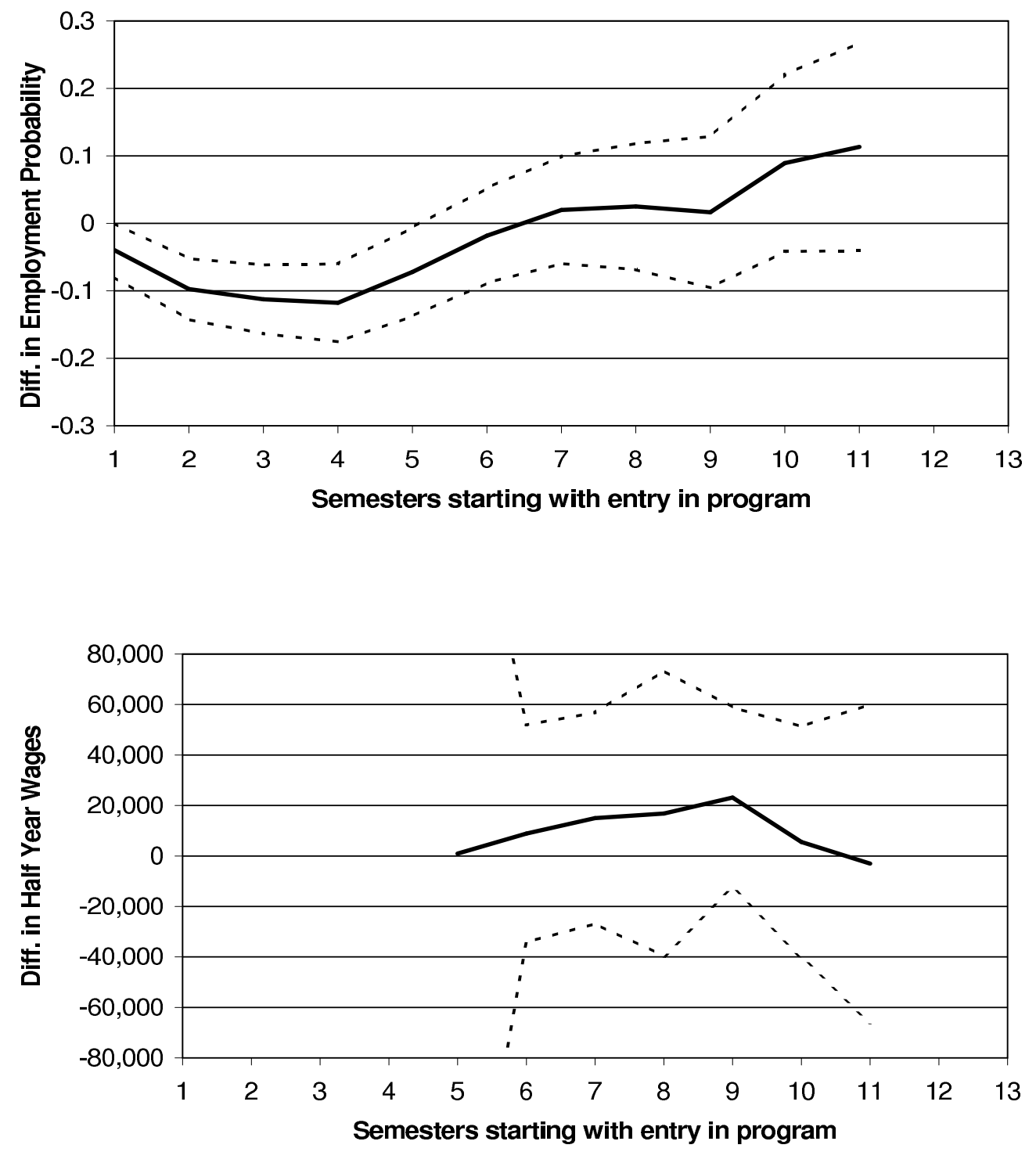

The estimation results by course types do not display much variation (see Figure 3 and 4). Courses with a significant amount of mathematics seem to improve employment and wages slightly less than other courses, while courses that include an orientation course seem to be slightly more beneficial. However, these differences are not significant. Notice that a comparison of ATT estimates across course types effectively amounts to a comparison of different subsets of treated individuals. 
Figure 6: Average Treatment-on-the-Treated Effect on Employment, if Out-ofthe-Labor-Force before Participation in Komvux - Average over All Program Types

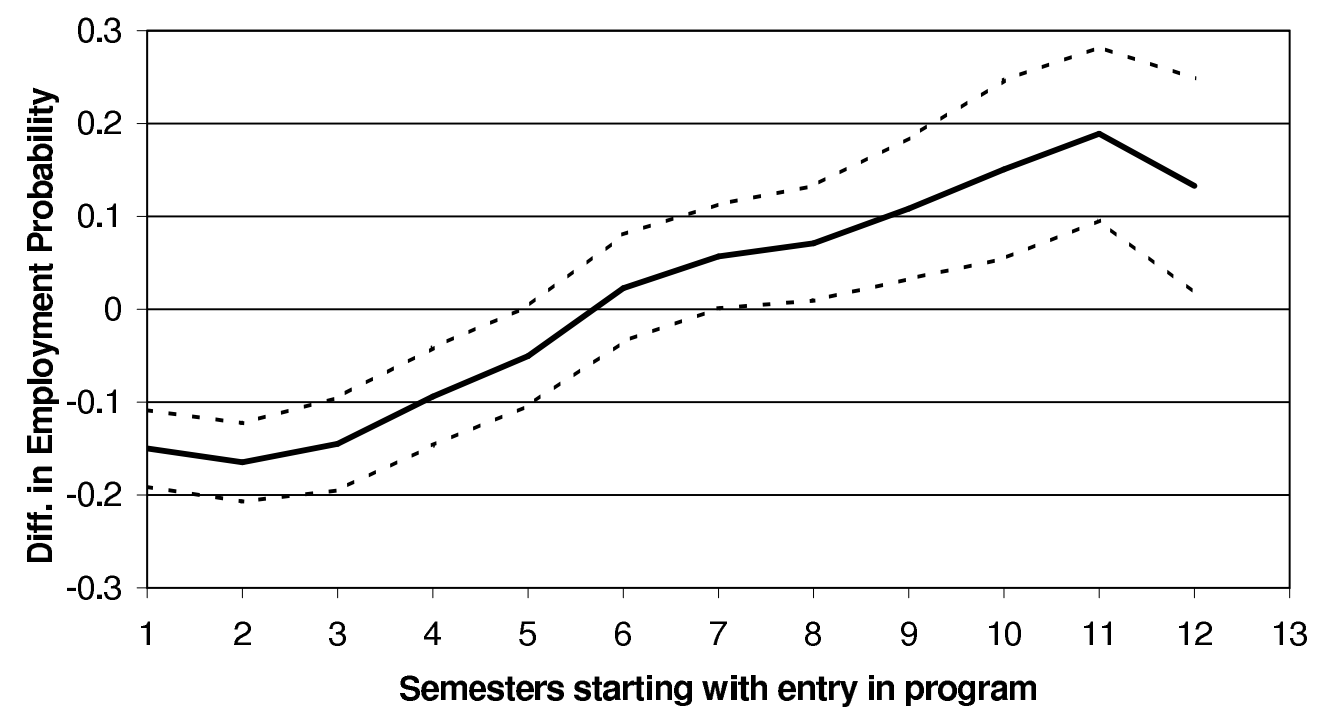

It is conceivable that certain population groups benefit more from adult education more than others. We therefore estimated the treatment effect separately for Non-Scandinavian women. Indeed, the point estimates indicate mostly a sightly higher treatment effect, although they are never significantly different from zero. The size of the subsample of Non-Scandinavian women may simply be too small for meaningful inference.

Women who are out of the labor- force before attending Komvux display quite a different structure of the treatment effects than women who are unemployed or in parental leave. A positive treatment effect only shows up by way of an increase of the employment probability. The size of this effect has, however, quite a considerable size with about 15 percentage points 5 years after the start. In contrast the effect on wages is relatively close to zero and at no point statistically significantly. 
Figure 7: Average Treatment-on-the-Treated Effect on Wage, if Out-of-theLabor-Force before Participation in Komvux - Average over All Program Types

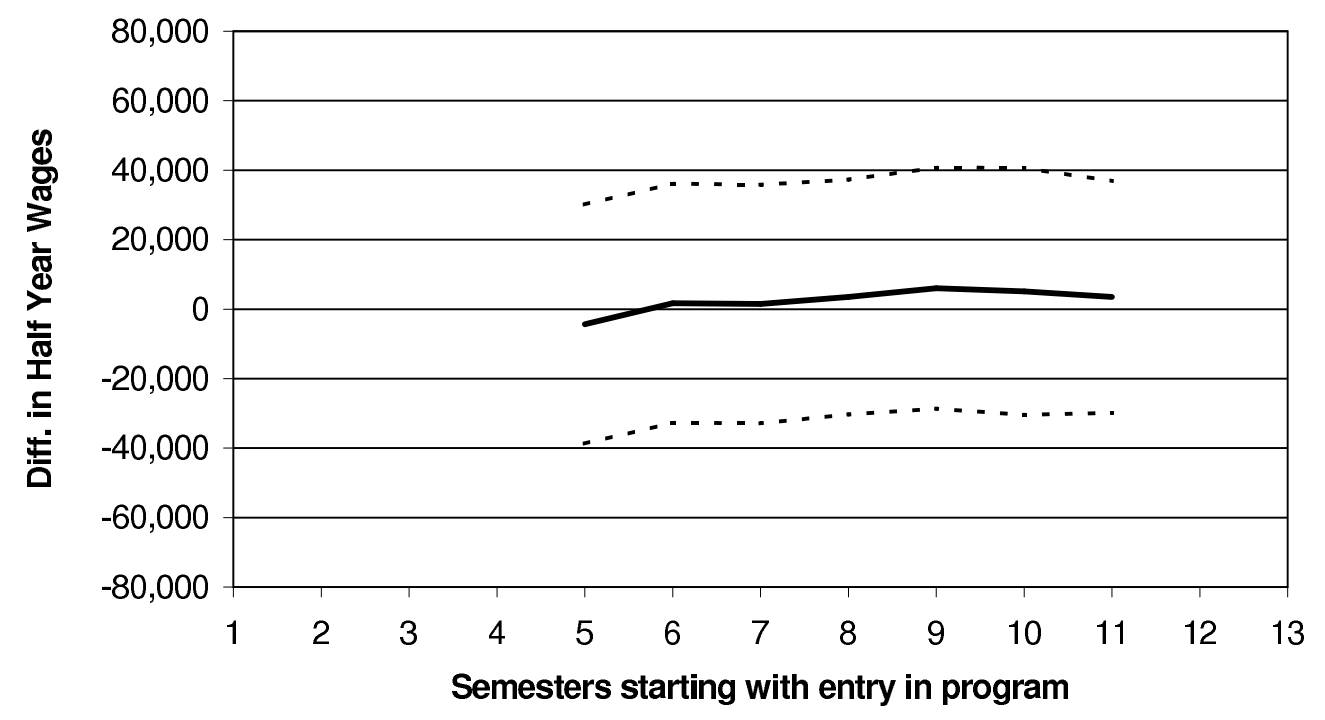

\section{Calibration of a model of job search and adult education}

\subsection{Job search model}

A major puzzle emerging from the previous section is why not more women participate in adult education. Less than $20 \%$ per semester flow into Komvux even though entry is not restricted and the average effects on the treated are quite large. Moreover, the vast majority (88\%) of those who do go into Komvux receive UBS or a similar grant, so it is unlikely that the low inflow for the average women is due to rationing of the income support grants.

To understand the enrollment decision, we examine the costs and benefits of different options at the individual level, using a dynamic job search model. Job search theory tries to describe the behavior of unemployed individuals in a dynamic and uncertain environment. We develop a job search model that allows for participation in adult education before finding a job, and that also takes account of other relevant institutional and behavioral aspects of the labor market for reintegrating mothers. The model is in discrete time, with a semester as the time unit.

Consider first the process leading to employment, in absence of an adult edu- 
cation program, for an unemployed woman who has given birth and has completed a fixed time in parental leave. Job offers arrive at random moments in time. If one is not employed then in every period there is a probability $\lambda$ that an offer arrives. Jobs pay a wage $w$. In line with the theoretical and empirical literature on search theory, we do not distinguish jobs by the weekly number of hours worked. Equivalently, we assume that all jobs are full-time jobs. Individuals do not know in advance when job offers arrive. Every time an offer arrives, the decision has to be made whether to accept it or to reject it and search further. We assume that once a job is accepted it will be kept forever at the same wage. During unemployment, per-period income $b$ is received.

Unemployed individuals aim at maximization of their own expected present value of utility over an infinite horizon. We assume that utility is intertemporally separable and equals the instantaneous income flow $w$ in case one works at a wage $w$ and $b$ in case one is out of work. Clearly, in the absence of wage dispersion, any sufficiently high fixed value of $w$ leads to acceptance at the first possible moment.

Let $r$ be the rate of discount (meaning that utility one period ahead has weight $1 /(1+r)$ in the current present value), and let $R$ denote the expected present value when following the optimal strategy. We assume that the model is stationary (see e.g. Eckstein and Van den Berg, 2007). It follows that

$$
R=b+\frac{\lambda}{1+r} \max \left\{\frac{(1+r) w}{r}, R\right\}+\frac{1-\lambda}{1+r} R
$$

We now introduce adult education into the model. Consider first the "treatment effects" of having participated in adult education. We allow program participation to affect both the per-period probability of receiving a job offer and the wage offer. The latter reflects any productivity differences due to the human capital accumulation in adult education. The former reflects the corresponding increase in the number of suitable vacancies. It also reflects any job search assistance efforts that are made because of the program participation. For example, the case worker of the individual may make additional efforts to find a job for the individual upon finishing program participation. Richardson and Van den Berg (2008) argue that this is the major reason for the fact that unemployed individuals in Sweden have a higher exit rate to work after a spell of labor market training. We use an index $i$ in $\lambda_{i}$ and $w_{i}$ to denote whether the structural determinant refers to the periods before $(i=0)$ or after $(i=1)$ program participation. Participation in Komvux takes 2 periods. We assume that individuals do 
not enter Komvux for a second participation spell.

Now consider the program enrollment process and childbirth. We extend the model, by allowing for 4 states: K, U, E and P, denoting Komvux, Unemployment, Employment, and Parental leave, respectively. We again consider a mother without employment having just completed her spell in P. In accordance to the actual Komvux setting, we assume that she can move into $\mathrm{K}$ in every time period, provided that she is unemployed. For convenience we assume that the decision to enroll and the decision to accept or reject a job offer are sequential. That is, before having received any job offer in a given period, the individual decides whether to enroll or not. If the individual does not choose $\mathrm{K}$ then she moves into $\mathrm{U}$ for the rest of the semester. Since the model is stationary, the decision to go into Komvux is essentially made right after having left $\mathrm{P}$. If it is not optimal to enter Komvux at that moment then it is never optimal afterwards.

Having another child is modelled as the outcome of a process during U. Specifically, during $\mathrm{U}$, a birth occurs with probability $\zeta$. Birth is followed by 2 periods in $\mathrm{P}$, and then by entry into U. Also, after $\mathrm{K}$, the individual moves into U. We may allow for a transition rate from $\mathrm{E}$ back into $\mathrm{U}$, but that would complicate the numerical analysis while for reasonable orders of magnitude the numerical results on the decision for or against $\mathrm{K}$ are barely influenced by it. As we shall see in the next subsection, the value of this transition rate does play a role in the calibration of the model.

During $\mathrm{K}$, the woman receives income support $z$, while during $\mathrm{P}$ she receives parental leave benefits $p$. In $\mathrm{K}$ and in $\mathrm{E}$, the woman incurs child care costs $c$.

Let $R_{0}$ denote the expected present value of $\mathrm{U}$ after having decided not to enroll into $\mathrm{K}$, and let $\widetilde{R_{0}}$ denote the present value upon leaving $\mathrm{P}$, before having decided whether to enroll into K. Next, let $R_{1}$ denote the expected present value after $\mathrm{K}$. Furthermore, let $P_{i}$ denote the present value upon entering $\mathrm{P}$, where $i=1(i=0)$ if the individual has (has not) participated in $\mathrm{K}$ since the birth of the previous child. Equation (1) is now replaced by the following set of Bellman equations,

$$
\begin{gathered}
R_{i}=b+\frac{\lambda_{i}}{1+r} \cdot \frac{(1+r)\left(w_{i}-c\right)}{r}+\frac{\left(1-\lambda_{i}\right) \zeta}{1+r} P_{i}+\frac{\left(1-\lambda_{i}\right)(1-\zeta)}{1+r} R_{i} \quad(i=0,1) \\
P_{i}=p+\frac{p}{1+r}+\frac{1}{(1+r)^{2}} R_{i} \quad(i=0,1)
\end{gathered}
$$




$$
\widetilde{R_{0}}=\max \left\{R_{0}, z-c+\frac{z-c}{1+r}+\frac{1}{(1+r)^{2}} R_{1}\right\}
$$

The individual chooses for $\mathrm{K}$ if and only if the first term in the right-hand side of (4) is smaller than the second term.

It is clear from (2) that the size of $\lambda_{1}-\lambda_{0}$ summarizes the employment effect of $\mathrm{K}$, while $w_{1}-w_{0}$ equals the wage effect. So far, we have not considered that individuals may move from employment back into unemployment. Suppose this occurs at the rate $\delta$. Then the steady-state employment rate equals $\lambda_{i} /\left(\lambda_{i}+\delta\right)$. The latter is a non-linear function of $\lambda_{i}$. At typical values of $\lambda_{i}$ and $\delta$ (e.g. $\lambda_{i}=0.1 \delta=1$ per semester, resulting in steady-state employment rate values of 90\%; see e.g. Ridder and Van den Berg, 2003), the derivative of the employment rate with respect to $\lambda_{i}$ is very small. This means that a small increase in the employment rate is mirrored by a large increase in $\lambda_{i}$. In particular, a small difference between the long-run employment rates of Komvux participants and Komvux non-participants may go along with a large difference $\lambda_{1}-\lambda_{0}$. At the same time, a large difference $\lambda_{1}-\lambda_{0}$ may imply a large difference between the present values $R_{0}$ and $R_{1}$ of the unemployed in the two groups. To see this, notice that present values assign higher weights to events in the near future. A high job offer arrival rate means a shorter average duration of the current unemployment spell, and therefore a shorter waiting time until the income flow is increased. ${ }^{11}$

We can extend the model further by allowing for transitions into non-participation. The simplest way to do this is to introduce an additional exit state with corresponding exit probability, by analogy to Van den Berg (1990). Moreover, we can make it optimal for women to move into $\mathrm{K}$ some semesters after parental leave rather than immediately, by allowing for sources of non-stationarity into the model. ${ }^{12}$ However, the former would lead to problems with calibrating the model (see the next subsection). The latter would complicate the model substantially, presumably without generating major additional insights (see again the next subsection). Another extension would be to allow for wage dispersion. In that case, the comparative statics effects of $\lambda_{1}-\lambda_{0}$ and $w_{1}-w_{0}$ are described in Van den Berg (1994) and Burdett (1981), respectively.

\footnotetext{
${ }^{11}$ It is not difficult to demonstrate this formally, using the equations in this subsection.

${ }^{12}$ Some structural empirical studies have estimated job search models that are somewhat similar to ours, in that they allow women to choose at any time for an outside option (Frijters and Van der Klaauw, 2006) or allow for participation in training programs (Adda et al., 2006).
} 


\subsection{Calibration}

In this subsection we quantify the model and we infer the implications for the enrollment decision. We quantify the variables or parameters $b, w_{0}, p, z, c$, and $\zeta$ by using averages of the data at our disposal. Next, we quantify $\lambda_{0}$ from external sources, and we quantify $\lambda_{1}-\lambda_{0}$ and $w_{1}-w_{0}$ using the estimates from the previous section. Table 10 gives the results of this procedure. In the absence of reliable information on the discount rate $r$, we consider a range of values for this parameter. In general, the quantification of the model depends on a range of debatable assumptions, as does the model specification itself. It is therefore important to point out in advance that the main qualitative conclusions are very robust with respect to all this.

We now describe in some detail the subsamples used to quantify $b, w_{0}, p, z, c$, and $\zeta$. The variable $b$ is taken to be the average Unemployment Insurance (UI) benefits level among women who receive UI. Some individuals without work do not qualify for UI, and it is difficult to assign an income level to them. For example, their subsistence may be supported by a fraction of the income of other household members. To avoid such ad-hoc procedures, we restrict attention to UI recipients. We take the average semesterly UI receipt over semesterly U spells per individual, and we subsequently average over individuals. The parental leave benefits $p$ and the Komvux income grant $z$ are quantified in essentially the same way, excluding Komvux spells without any income grant. The wage rate $w_{0}$ is the average semesterly wage among women in $\mathrm{E}$ in the semester before the childbirth of interest. The child care costs are quantified as the average in case of having two children and using care for 40 hours per week. The rate $\zeta$ of bearing an additional child is taken as the semesterly average over 3 to 13 semesters after the childbirth of interest.

The employment states and transitions shortly before and after childbirth are not suitable for the quantification of the transition rate $\lambda_{0}$ from $U$ to $E$, because of the dip in employment around the date of childbirth, and because spells out of work can be labor-market non-participation spells. We therefore rely on information in Albrecht, Van den Berg and Vroman (2008) instead. They calibrate a job search model using Swedish data from 1996, i.e. right before our Komvuxspells observation window. They distinguish between different skill levels, and for our purposes we only have to focus on low-skilled workers and low-skilled jobs. Their continuous-time transition rate from $\mathrm{U}$ to $\mathrm{E}$ equals 1.867 per year, 
Table 10: Calibration input values

\begin{tabular}{lr}
\hline \hline \\
unemployment benefits $b$ & 41,858 \\
wage rate $w_{0}$ without Komvux & 63,508 \\
parental leave benefits $p$ & 51,651 \\
Komvux income grant $z$ & 42,780 \\
child care costs $c$ & 12,120 \\
next-child birth rate $\zeta$ & 0.03 \\
job offer arrival rate $\lambda_{0}$ without Komvux & 0.607 \\
& \\
\hline & \\
wage rate $w_{1}$ after Komvux & 73,198 \\
job offer arrival rate $\lambda_{1}$ after Komvux & 0.690 \\
\hline
\end{tabular}

which implies that the probability that $U$ is left within 6 months equals 0.607 . We take this to equal our $\lambda_{0}$. In order to calculate $\lambda_{1}$ from the employment effect of Komvux as estimated in the previous section, we also need to quantify the transition rate $\delta$ from $\mathrm{E}$ to $\mathrm{U}$. (For expositional convenience, we imposed $\delta=0$ in our model, but this can be relaxed without computational cost, and in any case the qualitative results do not depend on this apart from the quantification of $\lambda_{1}$.) Following the same procedure as for $\lambda_{0}$, we derive from Albrecht, Van den Berg and Vroman (2008) the value of 0.0842 for $\delta$. Subsequently, $\lambda_{1}$ follows from the estimation result that $\left(\lambda_{1} /\left(\lambda_{1}+\delta\right)\right)-\lambda_{0} /\left(\lambda_{0}+\delta\right)=0.013$, where the latter number is the ATT estimate averaged over 5 to 13 semesters after inflow into K. This gives $\lambda_{1}=0.690$. Finally, the post-Komvux wage rate $w_{1}$ follows from the ATT estimate averaged over 5 to 13 semesters after inflow into K.

Table 11 gives the results for the model outcomes, for two discount rates: 0.05 per semester and 0.20 per semester. The first value is conventional, and we take the corresponding results as our baseline calibration results. The variable $\operatorname{EPV}(\mathrm{K})$ is the expected present value of choosing to enroll in Komvux, i.e. the second term in the right-hand side of (4). Clearly, the difference between $R_{0}$ and $\mathrm{EPV}(\mathrm{K})$ is of particular interest, as this determines the choice for or against 
Table 11: Calibration results

\begin{tabular}{lrr}
\hline \hline & $r=0.05$ & $r=0.20$ \\
& & \\
$R_{0}$ & 1064 & 294 \\
$R_{1}$ & 1255 & 340 \\
$\mathrm{EPV}(\mathrm{K})$ & 1198 & 293 \\
$\widetilde{R_{0}}$ & 1198 & 294 \\
& & \\
\hline corresponding flow values: & & \\
& & \\
$r R_{0} /(1+r)$ & 50.7 & 49.0 \\
$r R_{1} /(1+r)$ & 59.8 & 56.7 \\
$r$ EPV $(\mathrm{K}) /(1+r)$ & 57.1 & 48.8 \\
$r \widetilde{R_{0}} /(1+r)$ & 57.1 & 49.0 \\
& & \\
\hline \hline & Note: the units are 1000 SEK and 6 months.
\end{tabular}

participation in Komvux.

The calibrated model unambiguously predicts that participation in Komvux is beneficial for the individual. Choosing for $\mathrm{K}$ does have two short-term disadvantages over entering U. First, $z-c<b$, so that the instantaneous income flow in $\mathrm{K}$ is smaller than in $\mathrm{U}$. Secondly, the individual is confined to $\mathrm{K}$ for two periods, whereas one may be able to leave $\mathrm{U}$ for $\mathrm{E}$ during any of these periods. However, these short-term disadvantages do not offset the long-run advantages of K. Once employed, the semesterly income is about SEK 10,000 higher if one has participated in $\mathrm{K}$. In present values, with $r=0.05$, this is an increase of almost SEK 200,000, or almost 20\%. From Table 11 it follows that the price to be paid for this improvement is only about SEK 50,000 of foregone earnings due to Komvux participation.

The final column of Table 11 gives calibration results for a 0.20 discount rate. This is a very high value; it implies indifference between having 1 krona in 12 months from now and having $1 /(1+r)^{2}=0.69$ kronor today. With such an unrealistically high $r$, the individual is virtually indifferent between going into Komvux and not going into it. The future rewards of participation are then insufficiently 
important to offset the short-run costs. In this case, with an "average" mother being indifferent, one would expect that about half of the relevant population of mothers would benefit from Komvux, whereas the net return would be negative for the other half. As the actual Komvux inflow rate is much lower than 50\%, it follows that even the $r=0.20$ scenario is not sufficiently extreme to explain why so few mothers enter Komvux in the context of our model. Evidently, there are strong non-pecuniary factors that make young mothers prefer not to enter Komvux. The alternative option of becoming unemployed or a non-participant in the labor market are more attractive because they deliver utility that is absent while being in Komvux. It is likely that this concerns the possibility to be home with the infant. Presumably, young mothers are willing to give up monetary advantages in return for being able to take care full-time of the infant after it has reached the age of one.

The option of entering Komvux can be made more attractive by increasing the income grant $z$ or by decreasing the child care costs while in Komvux. The size of the effect depends on the distribution of the unobserved utility that women attach to being able to stay home with their one-year old child. Moreover, the average treatment effects among the treated may decrease if the fraction of women entering Komvux increases.

From the discussion of the results in Table 11 it is clear that the qualitative implications of the baseline calibration are very robust to a range of assumptions. One simply needs drastically different parameter values in order to reverse the main predictions.

\section{Conclusions}

Among women who are without work after childbirth, participation in adult education has a significant positive causal effect on their labor market prospects. Both the wage rate and the employment rate are on average higher than in the counterfactual situation in which the mother does not follow adult education. This is important because women without work after childbirth sometimes do not qualify for labor market training and other programs to bring unemployed back to work. In such cases, adult education may be the only skill-enhancing program available. Moreover, direct costs of adult education are generally low or absent. In sum, adult education is a useful and accessible program to prevent 
young mothers from entering a downward spiral of joblessness and skill loss.

The positive effects of adult education have not led to a massive inflow into the program. To understand this, we calibrate a dynamic job search model that includes adult education as an option. We use income data in employment, unemployment, parental leave, and in adult education, as well as data on child care, and the estimated effects of adult education, to quantify the model. We find that adult education increases the individual's total expected discounted income. For an average individual, the short-run costs (lock-in time in education; child care while following education) are by far outweighted by the long-run advantages in terms of income. We conclude that there are strong non-pecuniary factors that make young mothers prefer not to enter adult education, notably the possibility to be home with the infant. Young mothers are willing to give up monetary advantages in return for being able to take care full-time of the infant after it has reached the age of one.

The option of entering adult education can be made more attractive by increasing the income grant or decreasing the child care costs while in education. It is an interesting topic for further research to investigate this further. For example, regional or temporal variation in child care costs and in the availability of income grants may be used to assess the role of this in the enrollment and the effects of adult education.

The link between the conditional difference-in-differences estimates of the treatment effects on the one hand and the economic model on the other hand led to some additional insights. First of all, in general, small effects on the employment probability may go along with larger effects on the expected discounted value of program participation and also with larger effects on the exit rate to work. This is because employment rates are typically unresponsive functions of the job offer arrival rate, and because present values assign higher weights to income in the nearest future than to income in the long run.

Secondly, wage rate outcomes do not display the post-program dip that is typically encountered in studies of effects on annual earnings. This is because the latter outcome is confounded by the sluggish employment adjustment whereas the wage rate outcome is not. It follows that wage data allow for a faster program evaluation than earnings data, if interest is in productivity effects. 


\section{A Data Appendix}

The basic sample consists of women who are low or medium skilled in 1996 and who gave birth in the time period from 1996 to 2004. We only consider prime aged women ( 25 to 45 years in 1996) for whom it is at most their fifth child. In total we observe 208.420 women fulfilling the selection criteria.

\section{A.1 KOMVUX}

The KOMVUX data is collected at a semesterly frequency, i.e. there are separate records for every semester and every course an individual participates in. Often, records already indicate if a course is supposed to last longer than one semester. Then the start and formal end date of records collected at consecutive semesters are the same. The separate records differ with respect to the information which changes over consecutive semesters as for example number of teaching hours. Sometimes, however, one record reports an end in one semester and another record reports a restart in the following semester. There are also cases where records report individuals attending a specific course type more than once in the same semester.

The data contains a drop-out date in case an individual ends a course prematurely. Note that there is no strict relationship with respect to the reported drop-out date and the semester for which the main part of the information is collected (in the following denoted as reporting semester). The drop-out date can lie during, before and after the reporting semester. There are also missings in the variables for the end date and drop-out date.

We observe 74,377 women of our basic sample attending the adult education program between II/1997 and II/2002.

We perform the following steps to make the data accessible for the analysis:

(i). We discard individuals permanently from our sample in case at least one of the following 4 conditions applies:

(a) Attending courses that started before II/1997: 3,114 women

(b) Attending courses that end after II/2002: 5,312 women

(c) Courses with missing end dates: 641 women

(d) Implausible start, end or dropout date (for example, courses with negative durations): 19 women 
Remaining women participating in adult education: 65,291 . The data set contains 813,541 different records describing their participation in adult education.

(ii). Records are discarded from the treatment sample, if the following applies:

(a) Start and end date coincide (2,597 records).

(b) Zero teaching hours (2,830 records).

(iii). Decisions and assumptions concerning the drop-out variable: On semester level $10 \%$ of the records report a drop out (85,003 records)

(a) In 5,156 cases the drop out occurs before or on the start date of the course. We delete these cases. 64,812 participating women remain.

(b) Drop-out dates can also lie after the formal end date (3,140 records). Individuals who drop out after the end date of the course always have a missing in their grade. We assume that these individuals participated in the course but did not successfully pass it.

(c) On the basis of the information on teaching hours and the drop-out date, a variable is created giving the hours of attendance. 1083 records have 0 hour of attendance. These cases were discarded. 64,803 participating women remain.

(d) We define a new end variable, providing information on the time an individual stopped attending a course. Consequently, in case an individual dropped out of a course before the formal end date, we use the drop-out date as the new end date.

Note that if due to (ii) and (iii) no record of participation for an individual is left, an individual is automatically defined as a Komvux nonparticipant and will appear in the sample of nonparticipants, whereas an individual who is discarded under the conditions of (i) is a participant for whom the information is incomplete or inconsistent. As a result she does not appear in the sample of nonparticipants.

(iv). Merging of records of the same course type:

(a) Double records concerning the same individual and the same time period are identified by way of the course code, number of high school 
points, number of hours taught, start date and semester reporting period. In the majority of case, double entries are due to individuals switching schools. We give priority to those records which have a valid grade.

(b) Records for the same individual with the same course code are merged to one spell if they lie within one uninterrupted participation spell in adult education. The records which are merged under this condition to one spell are denoted in the following as "merge set".

(c) Naturally, the start date of a merged spell is the earliest start date of all records in a merge set. The end date is the last date within the merge set, at which we observe an individual to attend the course. Furthermore, we report the total number of hours attended.

(d) As mentioned before, some records report start dates which lie before the reporting period and some records report end dates which lie after the reporting period. In the majority of cases we find fitting records in an earlier, respectively later reporting period. We define records as fitting if their reporting semester covers the start or respective end date in question. They do not necessarily need to have the same start or end date. However, this matching process does not work for small percentage of the course type specific participation spells. In those case, we give priority to the information which is related to the reporting semesters. As a result we set the start date of the spells that started before the reporting semester to the beginning of the earliest reporting semester within the merge set. Those spells that ended after the end of the last reporting semester are treated as dropouts at the end date of the last reporting semester within the merge set. 
(v). After the selection process of individuals, the following distribution of attended hours in adult education can be observed:

\begin{tabular}{l|ccc}
\hline \hline Hours attended & Freq. & Percent & Cum. \\
\hline-50 & 6,427 & 9.92 & 9.92 \\
$51-100$ & 4,923 & 7.60 & 17.51 \\
$101-250$ & 8,939 & 13.79 & 31.31 \\
$251-500$ & 10,137 & 15.64 & 46.95 \\
$501-750$ & 9,229 & 14.24 & 61.19 \\
$751-1000$ & 8,267 & 12.76 & 73.95 \\
$1001-1250$ & 5,576 & 8.60 & 82.56 \\
$1251-1500$ & 4,313 & 6.66 & 89.21 \\
$1501-1750$ & 2,699 & 4.16 & 93.38 \\
$1751-2000$ & 1,742 & 2.69 & 96.06 \\
$2000-$ & 2,550 & 3.94 & 100.00 \\
\hline Total & 64,802 & 100.00 & \\
\hline \hline
\end{tabular}

(vi). We receive the following distribution concerning program length. Note that individuals might have breaks in between:

\begin{tabular}{l|ccc}
\hline \hline $\begin{array}{l}\text { Program } \\
\text { duration }\end{array}$ & Freq. & Percent & Cum. \\
\hline 1 & 17,060 & 26.33 & 26.33 \\
2 & 15,892 & 24.52 & 50.85 \\
3 & 10,050 & 15.51 & 66.36 \\
4 & 6,907 & 10.66 & 77.02 \\
5 & 3,851 & 5.94 & 82.96 \\
6 & 3,285 & 5.07 & 88.03 \\
7 & 2,355 & 3.63 & 91.66 \\
8 & 2,039 & 3.15 & 94.81 \\
9 & 1,436 & 2.22 & 97.03 \\
10 & 1,153 & 1.78 & 98.81 \\
11 & 774 & 1.19 & 100.00 \\
\hline Total & 64,802 & 100.00 & \\
\hline \hline
\end{tabular}


(vii). We summarize course type specific participation into the four categorizes mathematics, Swedish and English, orientation courses, and all other courses. Dummies for participation in these groups are constructed according to proportion of attended hours:

\begin{tabular}{l|l}
\hline \hline Dummy $=1$ for & under the condition \\
\hline Mathematics & proportion of attended hours $>25 \%$ \\
Swedish and English & proportion of attended hours $>25 \%$ \\
Orientation Courses & proportion of attended hours $>0 \%$ \\
Other courses & proportion of attended hours $>25 \%$ \\
\hline \hline
\end{tabular}

\section{A.2 Employment and Wage Data (RAMS)}

The employment information and the wage data is taken from the wage information which firms are obliged to give to the tax authorities. For every calendar year, all firms have to inform the tax authorities about the employment duration of each employee (on a monthly basis) and on his/her yearly wage. This obligation determines the structure of the RAMS data which consists of separate registers for every year. The employment duration of an individual in a specific year is given by the start month and the end month. In addition, there is a variable for the wage paid during this employment relationship. We use the registers for the year 1994 until 2003.

Income from the social insurance, as for example parental benefits, is not covered by the data. An individual is counted as employed when being on parental leave, if s/he was employed shortly before. However, we can create maternity leave spells within the employment spells. Eriksson (2005) reports for 2001 an average length of maternity leave of 10 months within the first 18 months after child birth. We use this estimated number of 10 months as the maternity leave period length in our observation window period of child birth (1996 to 2001). The parentalleave compensation rate increased from $75 \%$ to $80 \%$ in this period, but apart from this the regulations did not change. Before 1996 and after 2001 the parental leave system was changed a number of times (see Table 2.3).

The benefits received during maternity leave will be calculated with the aid of an additional data set (LOUISE, see below).

With respect to the RAMS data on the months of employment, there are records where both, the variable for the start month and the variable of the end 
month, take the value 0 . In these cases we set the start month on January and the end month on December.

We exclude women who are self-employed or farmers (17,812 individuals). This results in 2,240.452 records for 185,300 individuals of our basic sample conditional on never being self-employed or farmer in time from 1994 to 2003. Naturally, individuals can have multiple employers in one calendar year. In order to exclude extreme outliers, we drop individuals from our sample with more than 10 employers in one year (365 individuals).

We split employer-specific employment spells into half-calendar-year long segments. We then aggregate employment spells which are parallel, partly overlapping or consecutive within the half calendar year periods. Finally, the average monthly wage is calculated.

\section{A.3 Unemployment spell data (HÄNDEL):}

Within HÄNDEL, two complementary registers describe unemployment spells. The first one is INSPER, describing the unemployment duration and the exit state after leaving unemployment. The second is SOKATPER. This describes the status during the unemployment spell. Unemployment states such as in guidance service, part-time unemployed and participation in a variety of ALMP are listed. We exclusively use the SOKATPER data set. The only additional information which INSPER could offer over SOKATPER is the exit state, which we know anyway by combining the unemployment spells with the employment spells. The unemployment data is reliable starting with 1993. However, we only consider unemployment spells starting after or ongoing on 01.01.1994 as the benefit data is only reliable after that date.

About $70 \%$ of the women in our basic sample $(146,056$ of 208,420$)$ have at least one unemployment spell during the time between 01.01.1994 until 31.03.04. In total we observe $1,506,581$ unemployment subspells. We delete those spells with a negative duration $(12,890)$. 
We summarized the unemployment states to the following aggregates:

\begin{tabular}{l|l}
\hline \hline Category & Unemployment state \\
\hline$(1)$ & unemployed \\
$(2)$ & $\begin{array}{l}\text { partly unemployed (=part-time unemployed or } \\
\text { employed by the hour) } \\
\text { searching for a new job } \\
(3)\end{array}$ \\
$(4)$ & $\begin{array}{l}\text { labor market training } \\
\text { other category not registered (other than 1,2,3,4,6) } \\
(5)\end{array}$ \\
\hline \hline
\end{tabular}

We split the unemployment (status) spells at the middle and the end of every calendar year in order to obtain outcomes on a half-year basis. This results in $2,288,085$ potentially split unemployment spells.

We then drop those unemployment status spells which indicate that individuals were searching for a new job while being employed. Furthermore, we exclude those individuals completely from our analysis who have category ' 5 ' spells, as we are not able to interpret them.

There is no regularity concerning how women are registered when being unemployed and giving birth to a child, although caseworkers are recommended to deregister individuals during the time of the maternity leave. Sometimes they continue to be registered as unemployed, although not receiving unemployment benefits. Sometimes they are changed to the status partly unemployed, often only for the first few months after child birth. We therefore also create maternity leave spells for unemployed women of 10 months of duration.

\section{A.4 Unemployment benefit registers (ASTAT):}

The unemployment benefit data stem from two different data bases. Together, they cover the unemployment benefit payments to all Swedish inhabitants in the time period from 1994 to 2004. The first register, ERSBET, covers mainly the time period from 1994 to 1999 . The second register, ASUBET, covers mainly the time period from 2000 to 2004. The benefit payments are reported by both registers on a weekly basis. The two registers are, however, somewhat different with respect to how and what kind of information is recorded. 


\section{A.4.1 ERSBET}

The structure of the data is such that on an individual level for each calendar week the number of compensation days for a specific type of compensation is mentioned together with the amount paid for this week. For our basic sample there are 9,012,082 different records of benefit payments. 8644 of those are double entries. A double entry occurs if there are two records for the same type of compensation made to the same individual for the same calendar week. We keep the last added observation.

There are missings in the variable for benefit payments. This is, however, exclusively the case when a time interval is described as waiting period. Therefore we set these cases on a zero benefit level. Sometimes, several records are reported for one calendar week. The main reason for this lies in the fact that on different days of the week individuals are eligible for different types of compensations. There are also specific payment combinations which can occur at the same time. We add payments of parallel records and keep only the aggregated record. This reduces the number of observations to $8,575,751$.

\section{A.4.2 ASUBET}

For our basic sample we receive 5,789,769 records in ASUBET. The data set contains a marker for individuals with double/wrong entries. We drop those individuals (18 individuals with 1,175 records). The data set does not have missing values in the variable for the benefit payments. We identify additional 58,075 double entries, of which we we keep the latest added entry. Furthermore, we aggregate parallel entries by adding the benefit payments. In total we end up with $5,626,984$ records.

\section{A.4.3 Merging of Unemployment Benefit Data Sets}

ERSBET and ASUBET partly cover the same individuals. In case there are duplicate records, we keep those from ASUBET. In total there are 1,336,357 duplicate records. We keep in total 12,866,399 records.

\section{A.5 Merging of Benefit and Unemployment Spell Data}

The aggregated unemployment status data is the reference point for the merge process of the unemployment and the benefit data. We restrict our data to the end 
of 2003, to be precise until 29.12.2003 which is the end of a calendar week. After dropping those individuals who were excluded during the cleaning process of the benefit data, we obtain in total 2,241,098 unemployment status spells for 145,249 individuals and 12,083,677 benefit spells for 178,466 individuals. We merge the weekly benefit data to the aggregated unemployment state data if they overlap for at least 4 days. On the basis of this 4 day criterion 74,461 unemployment benefit records can not be merged to an unemployment spell. For those records we reduce the merge criterion to an overlap of at least one day. If the benefit spell overlaps with more than one unemployment state spell it is only merged to the first overlapping unemployment state spell. This additional one day criterion reduces the benefit records which can not be merged to 54,025. In the third step, also benefit records which are not allocated yet, are merged to unemployment spells which directly succeed or precede. In total, for 4,470 individuals we are not able to allocate on average about 11 weeks of benefit records. We drop these individuals completely from our analysis.

We calculate the average monthly benefit payments for the unemployment spells which are a maximum of 6 months long on the basis of the following formula (sum of benefit payments during the spell/number of days during spell)* $7^{*} 4.33$.

\section{A.6 Merging of Employment, Unemployment and Komvux Data}

In a first step we delete from our data base all observations from those individuals that we excluded for one of the above mentioned reason. Table 12 summarizes this sample selection process, together with additional selection criteria that are described in the main part of the paper (see Section 3.2). Note that individuals are only mentioned once here, although there can be multiple reasons why they are excluded. 
Merging the employment and the unemployment data is not straight forward, as there are time intervals where people are reported simultaneously as being unemployed and employed. We treat these parallel spells in the following way:

(i). If an unemployment status spell and an employment spell overlap for at most 30 days then the employment spell is shortened. The reason for this lies in the fact that we only have the monthly records for the employment data and the unemployment data is recorded daily. The calculated average monthly wage is adjusted accordingly.

(ii). We generate a new status "partly employed" (code 3) during an overlap of an unemployment status spell indicating "part-time unemployed" and an employment spell, if the overlap last longer than 30 days. For this time period we report the average income from employment and separately the average benefit payments.

(iii). For the time that there is an overlap of more than 30 days of an unemployment spell indicating fulltime unemployment and an employment spell, we define an overlap status "unemployed with side job" (code 0). Also for this time period we report the average income from employment and separately the average benefit payments.

For those time periods without records of unemployment or employment we create 'out of the labor market' spells. In case a mother gives birth during these 'out of the labor market' spells we automatically interrupted these spells by 10 months maternity leave spells.

Finally, we treat being in Komvux as a priority state that dominates all other states. In case a person is employed while being in Komvux the income is recorded accordingly.

\section{A.7 LOUISE-Data}

With the aid of the annual LOUISE data we define households in which the women live in, separately for each year. The LOUISE data set contains a family identification variable which defines a couple as a family in case they are married or live in a registered partnership or live together with a joined child. Children who live in the same house/appartment and are in some kind of financial dependency also belong to the household. With the aid of the family identification and 
Table 12: Selection

\begin{tabular}{|c|c|c|c|}
\hline Selection Criteria & Code & $\begin{array}{c}\text { Number of } \\
\text { Observations } \\
\text { Dropped }\end{array}$ & $\begin{array}{c}\text { Number of } \\
\text { Remaining } \\
\text { Observations }\end{array}$ \\
\hline $\begin{array}{l}\text { Basic Sample } \\
\text { Low and medium skilled } \\
\text { Birth between } 1996 \text { and } 2004 \text { (at } \\
\text { most fifth child) } \\
\text { Prime aged in } 1996 \text { ( } 25 \text { to } 45 \text { years) }\end{array}$ & & & \\
\hline Remaining sample & & & 208.420 \\
\hline $\begin{array}{l}\text { Restrictions Concerning } \\
\text { Consistency of Data } \\
\text { No participation spells in Komvux } \\
\text { that started before II/1997 } \\
\text { No participation spell in Komvux } \\
\text { that ended after II/2002 } \\
\text { Consistent data on Komvux } \\
\text { Consistent data on benefits } \\
\text { Consistent data for merging } \\
\text { benefits and Handel } \\
\text { Exclude self-employed and farmers } \\
\text { Consistent data on employment } \\
\text { Consistent data on HANDEL }\end{array}$ & $\begin{array}{c}(107) \\
(108) \\
(102-106,109) \\
(301) \\
(401) \\
(501) \\
(502) \\
(601)\end{array}$ & $\begin{array}{c}3,114 \\
5,312 \\
660 \\
18 \\
\\
4,212 \\
16,848 \\
341 \\
34\end{array}$ & \\
\hline Remaining sample & & & 177,881 \\
\hline $\begin{array}{l}\text { Participants (in the broader sense) } \\
\text { Participants (in the narrower sense) }\end{array}$ & & & $\begin{array}{l}58,576(\approx 33 \%) \\
23,066(\approx 13 \%)\end{array}$ \\
\hline $\begin{array}{l}\text { Additional Restriction on sample } \\
\text { Women not living with their parents } \\
\text { Women not deregistered from Sweden } \\
\text { Birth before } 2001 \\
\text { Only low skilled individuals } \\
\text { Women not entering university } \\
\text { during observation period }\end{array}$ & $\begin{array}{l}(95) \\
(96) \\
(97) \\
(98) \\
(801)\end{array}$ & $\begin{array}{r}5,368 \\
3,296 \\
34,916 \\
35,536 \\
6,394 \\
\end{array}$ & \\
\hline Remaining sample & & & 92,370 \\
\hline $\begin{array}{l}\text { Participants (in the broader sense) } \\
\text { Participants (in the narrower sense) }\end{array}$ & & & $\begin{aligned} 31,070 & \approx 34 \%) \\
12,717 & (\approx 14 \%)\end{aligned}$ \\
\hline
\end{tabular}


Table 12: Continued: Selection

\begin{tabular}{l|c|c|c}
\hline \hline Selection Criteria & Code & $\begin{array}{c}\text { Number of } \\
\text { Observations } \\
\text { Dropped }\end{array}$ & $\begin{array}{c}\text { Number of } \\
\text { Remaining } \\
\text { Observations }\end{array}$ \\
\hline \hline Repetition: Remaining sample & & & 92,370 \\
\hline \hline Further Restriction on Participation: & & & \\
Leading to Dropping Individuals from Sample & $(99)$ & 8,071 & \\
No participation before II/1997 & $(701)$ & 2,754 & \\
No participation during maternity leave & $(111)$ & 3,457 & \\
No participation before child birth & & & 78,067 \\
\hline \hline Remaining sample & & & $9,023(\approx 12 \%)$ \\
\hline Participants (in the broader sense) & & \\
\hline Participants (in the narrower sense) & & \\
\hline \hline
\end{tabular}

a variable defining the status the partner of the mother (to be) can be identified. In addition we drop cases for which we do not have observations for the whole time period (1996 to 2003), which can be due to death or emigration.

The LOUISE data set provides information on parental leave benefits on a yearly basis. We add the amount which is reported in the year of birth and the amount reported in the consecutive year. We then calculate a monthly average over the 10 month which we assume that women take maternity leave.

\section{A.8 Discrete Time Analysis}

\section{A.8.1 Definition of Employment States}

For the discrete time analysis we aggregate the spells into states of 6 month duration. We use the following settings to accomplish this: A period is defined as employed in case an individual was employed for more than $50 \%$ of the time. Hereby we weight the overlapping employment and unemployment spells in the following fashion: If somebody is defined as employed and unemployed she counts as $30 \%$ employed. If she is defined as employed and partly unemployed she counts as $50 \%$ employed. These weights take into consideration that the unemployment 
data is more reliable than the employment data with respect to the timing that labor market spell. Also the decision on that an individual has to be employed for more than $50 \%$ of the time in order to be count as employed is connected with the inaccuracy of the ANST data. In case a time period is not defined as employed, then it is either defined as in maternity leave, unemployed, or out of the labor force, depending which of each state is more prevailing. A women is defined as being in Komvux in case she attends a course of 2 to 4 semesters with more than 350 hours in total.

\section{A.8.2 Household Income}

The household income consists of a number of different income sources. The main components are the income from employment and the unemployment benefits. For the mothers (to be), these income sources are calculated as described above by way of the ANST data set and the HÄNDEL. The income from employment and the unemployment benefits of their partners are calculated in a similar way. We only do not exclude farmers and self employed or restrict the sample on 10 parallel spells per year when their income from employment is determined. Additional income sources, as social assistance, parental leave benefits, sickness allowance provided by LOUISE data are added. 


\section{References}

Adda, J., M. Costa Dias, C. Meghir, and B. Sianesi (2006), "Evaluating dynamic treatment: The Swedish active labour market programmes", Working paper, UCL and IFS, London.

Albrecht, J.W., G.J. van den Berg, and S.B. Vroman (2004), "The Knowledge Lift: The Swedish adult education program that aimed to eliminate low worker skill levels", Working paper, IFAU, Uppsala.

Albrecht, J.W., G.J. van den Berg, and S.B. Vroman (2008), "The aggregate labor market effects of the Swedish Knowledge Lift program", Review of Economic Dynamics, 11, forthcoming.

Axelsson, R. and O. Westerlund (1999), "Participants in the Knowledge Lift in autumn 1997 and comparison groups: labor market and income conditions before education", Working paper, Umeå University, Umeå (in Swedish).

Bennmarker, H., K. Carling, and B. Holmlund (2005), "Do benefit hikes damage job finding? Evidence from Swedish unemployment insurance reforms", Working paper, IFAU, Uppsala.

Bergemann, A., B. Fitzenberger, and S. Speckesser (2008), "Evaluating the dynamic employment effects of training programs in East Germany using conditional difference-in-differences", Journal of Applied Econometrics, forthcoming.

Bergemann, A. and G.J. van den Berg (2008), "Active labor market policy effects for women in Europe - a survey", Annales d'Économie et de Statistique, forthcoming.

Björklund, A., M. Clark, P.A. Edin, P. Fredriksson, and A. Krueger (2005), The Market comes to Education - An Evaluation of Sweden's Surprising School Reforms, Russell Sage Foundation, New York.

Burdett, K. (1981), "A useful restriction on the offer distribution in job search models", in G. Eliasson et al., editor, Studies in labor market behavior: Sweden and the United States, I.U.I., Stockholm.

Calmfors, L., A. Forslund, and M. Hemström (2001), "Does active labour market policy work? Lessons from the Swedish experiences", Swedish Economic Policy Review, 8, 61-124. 
Carling, K., B. Holmlund, and A. Vejsiu (2001), "Do benefit cuts boost job findings? Swedish evidence from the 1990s", Economic Journal, 111, 766-790.

Eckstein, Z. and G.J. van den Berg (2007), "Empirical labor search models: a survey", Journal of Econometrics, forthcoming.

Ekström, E. (2003), "Essays on inequality and education", Working paper, Uppsala University, Uppsala.

Eriksson, R. (2005), "Parental leave in Sweden: The effect of the second daddy month", Working paper, SOFI, Stockholm.

EUROSTAT (2003), "Labour market policy - qualitative report Sweden 2001", Working paper, EUROSTAT, Luxembourg.

Fay, R.G. (1996), "Enhancing the effectiveness of active labour market policies: Evidence from programme evaluations in OECD countries", Working paper, OECD, Paris.

Friberg, N. (2000), "Thematic review on adult learning: Sweden", Working paper, OECD, Paris.

Frijters, P. and B. van der Klaauw (2006), "Job search with nonparticipation", Economic Journal, 116, 239-277.

Heckman, J.J., H. Ichimura, J.A. Smith, and P. Todd (1998), "Characterizing selection bias using experimental data", Econometrica, 65, 1017-1098.

Heckman, J.J., R.J. LaLonde, and J.A. Smith (1999), "The economics and econometrics of active labor market programs", in O. Ashenfelter and D. Card, editors, Handbook of Labor Economics, Volume III, North-Holland, Amsterdam.

Heckman, J.J. and J.A. Smith (1999), "The pre-program earnings dip and the determinants of participation in a social program: implications for simple program evaluation strategies", Economic Journal, 108, 313-348.

King, C.T. (2004), "The effectiveness of publicly financed training in the United States: Implications for WIA and related programs", in C.J.. O'Leary et al., editor, Job Training Policy in the United States, 57-100, W.E. Upjohn Institute for Employment Research, Kalamazoo, Michigan.

Kolm, A.-S. and E. Lazear (2006), "Policies affecting work patterns and labor income for women", mimeo, Stockholm. 
Larsson, L. (2003), "Evaluation of Swedish youth labour market programmes", Journal of Human Resources, 38, 891-927.

Lundin, D., E. Mörk, and B. Öckert (2007), "Do reduced child care prices make parents work more?", Working paper, IFAU, Uppsala.

Martin, J.P. and D. Grubb (2001), "What works and for whom: a review of OECD countries' experiences with active labour market policies", Swedish Economic Policy Review, 8, 9-56.

Ministry of Education (1998), "Adult education and life long learning. the situation before and during the first year of the Knowledge Lift", Working paper, Ministry of Education, Sweden, Stockholm (in Swedish).

Ministry of Education (2005), "Quality in pre-school", A summary of government bill 2004/05:11, Ministry of Education, Sweden, Stockholm.

Ministry of Health and Social Affairs (2001), "Social insurance in Sweden", fact sheet, Ministry of Health and Social Affairs, Stockholm.

Ministry of Health and Social Affairs (2003), "Swedish family policy", fact sheet, Ministry of Health and Social Affairs, Stockholm.

Ministry of Health and Social Affairs (2005), "Swedish family policy", fact sheet, Ministry of Health and Social Affairs, Stockholm.

Ministry of Industry (2001), "Sweden's action plan for employment", Working paper, Ministry of Industry, Sweden, Stockholm.

National Agency for Education (1999), The Adult Education Initiative, National Agency for Education, Stockholm.

National Social Insurance Board (2001), Social insurance in Sweden 2000, National Social Insurance Board, Stockholm.

National Social Insurance Board (2002), Social insurance in Sweden 2001, National Social Insurance Board, Stockholm.

National Social Insurance Board (2003), Social insurance in Sweden 2002, National Social Insurance Board, Stockholm.

National Social Insurance Board (2004), Social insurance in Sweden 2003, National Social Insurance Board, Stockholm.

National Social Insurance Board (2005), Social insurance in Sweden 2004, National Social Insurance Board, Stockholm. 
OECD (2002), Employment Outlook 2002, OECD, Paris.

OECD (2004), Employment Outlook 2004, OECD, Paris.

OECD (2007), Employment Outlook 200\%, OECD, Paris.

Regnér, H. (2002), "Changing conditions for labor market policy", in J. Palme et al., editor, Welfare Conditions, 81-118, Socialdepartementet, Stockholm (in Swedish).

Richardson, K. and G.J. van den Berg (2008), "Duration dependence versus unobserved heterogeneity in treatment effects: Swedish labor market training and the transition rate to employment", Working paper, IFAU, Uppsala.

Ridder, G. and G.J. van den Berg (2003), "Measuring labor market frictions: a cross-country comparison", Journal of the European Economic Association, 1, $224-244$.

Silverman, B.W. (1986), Density Estimation for Statistics and Data Analysis, Chapman and Hall, London, New York.

Skolverket (2001), "The Knowledge Lift and upper secondary adult education Fall 2000", Working paper, Skolverket, Stockholm (in Swedish).

Skolverket (2003), "Fees in the pre-school and after school child care system", Working paper, Skolverket, Stockholm (in Swedish).

Statistics Sweden (2005), A longitudinal database on education, income and taxes (LOUISE) 1990-2002, Statistics Sweden, Stockholm (in Swedish).

Statskontoret (1999), "How much does the Knowledge Lift cost?", Working paper, Statskontoret, Stockholm (in Swedish).

Stenberg, A. (2003), "An evaluation of the adult education initiative relative labor market training", Working paper, Umeå University, Umeå.

Stenberg, A. and O. Westerlund (2008), "Does comprehensive education work for the long-term unemployed?", Labour Economics, 15, 54-67.

Swedish Institute (1997a), "Swedish labor market policy", fact sheet, Swedish Institute, Stockholm.

Swedish Institute (1997b), "Equality between women and men", fact sheet, Swedish Institute, Stockholm.

Swedish Institute (2000), "Equality between women and men", fact sheet, Swedish Institute, Stockholm. 
Swedish Institute (2001), "Swedish labor market policy", fact sheet, Swedish Institute, Stockholm.

Swedish Institute (2004), "Child care in Sweden", fact sheet, Swedish Institute, Stockholm.

Swedish Institute (2005), "Swedish labor market policy", fact sheet, Swedish Institute, Stockholm.

Van den Berg, G.J. (1990), "Search behaviour, transitions to nonparticipation and the duration of unemployment", Economic Journal, 100, 842-865.

Van den Berg, G.J. (1994), "The effects of changes of the job offer arrival rate on the duration of unemployment", Journal of Labor Economics, 12, 478-498. 